Article

\title{
Impact of the COVID-19 Lockdown on the Electricity System of Great Britain: A Study on Energy Demand, Generation, Pricing and Grid Stability
}

\author{
Desen Kirli *(D), Maximilian Parzen (D) and Aristides Kiprakis \\ Institute for Energy Systems, School of Engineering, University of Edinburgh, Edinburgh EH8 9YL, UK; \\ m.parzen@sms.ed.ac.uk (M.P.); kiprakis@ed.ac.uk (A.K.) \\ * Correspondence: desen.kirli@ed.ac.uk
}

Citation: Kirli, D.; Parzen, M.; Kiprakis, A. Impact of the COVID-19 Lockdown on the Electricity System of Great Britain: A Study on Energy Demand, Generation, Pricing and Grid Stability. Energies 2021, 14, 635. https://doi.org/10.3390/en14030635

Received: 11 November 2020 Accepted: 18 January 2021 Published: 27 January 2021

Publisher's Note: MDPI stays neutral with regard to jurisdictional clai$\mathrm{ms}$ in published maps and institutional affiliations.

Copyright: (C) 2021 by the authors. Licensee MDPI, Basel, Switzerland. This article is an open access article distributed under the terms and conditions of the Creative Commons Attribution (CC BY) license (https:// creativecommons.org/licenses/by/ $4.0 /)$.

\begin{abstract}
The outbreak of SARS-COV-2 disease 2019 (COVID-19) abruptly changed the patterns in electricity consumption, challenging the system operations of forecasting and balancing supply and demand. This is mainly due to the mitigation measures that include lockdown and work from home (WFH), which decreased the aggregated demand and remarkably altered its profile. Here, we characterise these changes with various quantitative markers and compare it with prelockdown business-as-usual data using Great Britain (GB) as a case study. The ripple effects on the generation portfolio, system frequency, forecasting accuracy and imbalance pricing are also analysed. An energy data extraction and pre-processing pipeline that can be used in a variety of similar studies is also presented. Analysis of the GB demand data during the March 2020 lockdown indicates that a shift to WFH will result in a net benefit for flexible stakeholders, such as consumers on variable tariffs. Furthermore, the analysis illustrates a need for faster and more frequent balancing actions, as a result of the increased share of renewable energy in the generation mix. This new equilibrium of energy demand and supply will require a redesign of the existing balancing mechanisms as well as the longer-term power system planning strategies.
\end{abstract}

Keywords: electricity system; COVID-19; electricity demand; energy; demand; behaviour; lockdown; electricity pricing

\section{Introduction}

The outbreak of coronavirus disease 2019 (COVID-19) led to a lockdown on Wednesday, the 23rd of March 2020 in the United Kingdom (UK). The government instructed that people should leave their homes only for purchasing necessities and exercising. People were only allowed to go to work if working from home (WFH) was not possible. Failing to follow the new lockdown measures would lead to fines [1]. The strict lockdown ended on Sunday, 10th of May and was replaced with a range of looser measures for the containment of the disease. However, WFH has become the new norm. These measures lead to a disruptive change in the electricity demand and influenced the wider energy sector. Energy companies in the UK warned about potential blackouts [2]. The analysis of this high impact and low probability event is significant as any adverse effects on the electricity sector due to future pandemics or lockdowns could be forecast using the insights of this analysis.

Studies such as [3] investigate ways to improve the power system resilience for high impact and low probability events under future climate and extreme weather conditions. However, the impact of a pandemic such as the one experienced with COVID-19 is still unclear. The changes and trends in energy due to the pandemic are identified for demand [4,5], generation, grid stability [5] and various power markets [6,7]. Most of the aforementioned analyses quantify changes by determining absolute or percentage change between pre- and post-lockdown periods. 
As noted in [4], all analyses should be addressed with caution, since comparing different timeframes in power systems is a challenge due to various distorting factors that play a role such as weather, human behaviour and economic climate.

As a result, this study seeks to analyse the changes in demand, generation, grid stability and market prices in a quantitative manner where changes are striking and choosing a qualitative approach where the difference is ambiguous.

The main contribution of this paper is the systematic observation and analysis of the effects of the COVID-19 lockdown in Great Britain on demand and operation of the electrical power network, during its early weeks. Secondarily, we present the electricity data pipeline employed for our analysis, which is also made available as open source. The main highlights of this work are the following:

- This analysis characterises the changes in aggregate demand magnitude and profile due to the lockdown with various quantitative markers such as load duration curve, statistical distribution analysis and others.

- The ripple effects on the generation portfolio, system frequency, forecasting accuracy and imbalance pricing are also evaluated.

- The effect of the lockdown on domestic consumers on a variable energy tariff is identified and over 70 occurrences of negative pricing were detected.

- The implications of the lockdown are discussed for different stakeholders including generators, industrial and commercial consumers, domestic consumers on both fixed and variable tariffs, aggregators and demand-side response providers.

- The possibility of the lockdown data being an outlook for the future electricity system in terms of flatter demand profile and increased contribution from the variable renewable generators is discussed.

- The electricity data extraction and pre-processing pipeline that can be used in a variety of similar studies is presented.

\section{Methodology}

In order to analyse the impact of the COVID-19 lockdown on the electricity market, a systematic approach is used which involved creating an efficient pipeline to extract the target data, pre-process, analyse and visualise. In this section, the methodology used in the pipeline is explained. The instructions for future use are detailed using a flow diagram. The Python code employed can be accessed at the GitHub repository [8]. Both pure Python (i.e., py) and interactive Python notebook (i.e., ipynb) formats are made available. This pipeline was used to create a clean and filtered dataset that consists of all of the data used in the plots and analyses in this paper. This dataset is deposited in a public DataShare repository—see [9].

\subsection{Function of the Data Pipeline Code}

As this study involves a comparative analysis, various actions, such as cleaning the data and calculating the percentage differences, had to be repeated for different data sets such as frequency and demand. In order to minimise the time spent from the import of the data to the analysis and visualisation stages, a data pipeline on Python was programmed to fetch the data directly using the application programming interface (API) of the providersee [8].

This process is also commonly referred to as scripting, extracting and scraping the data. The pipeline is used for analysing the system frequency, demand, generation and other types of data and all results are presented in Section 3. It performs the following steps listed below.

1. Import the data from the source webpage using the API user key.

2. Identify the keywords and group the data.

3. Create weekly data frames (according to the Monday-to-Sunday convention (i.e., ISO 8601)).

4. Check for zeros, invalid or duplicate data.

5. Label and discard the columns that are not of interest. 
6. Adjust the date and time format (e.g., change from half-hourly settlement period convention (where 01:00 is denoted by 2) to time).

7. Save the adjusted data in CSV format with an automated title (DataLabel_Week_starting_StartDate.csv).

8. Calculate statistical and other quantitative descriptors such as mean, peak-to-mean ratio, etc.

9. Produce comparative visualisations of the data.

\subsection{Other Uses of the Data Pipeline}

In most of our analysis cases, the data source is the Balancing Mechanism Reporting Service (BMRS) [10]. The website [11] provides open-source data that are used for balancing and settling the GB electricity system.

The data provided (e.g., system demand, frequency, generation by fuel type, etc.) are used for reaching trading decisions and analysing the dynamics of market volumes and pricing. Since we believe that this pipeline which enables easy data extraction, pre-processing and visualisation may be useful for both academic and industrial researchers who are interested in electricity market dynamics, regulation, trading and forecasting. A flowchart is presented in Figure 1 which displays the steps required to replicate the results.

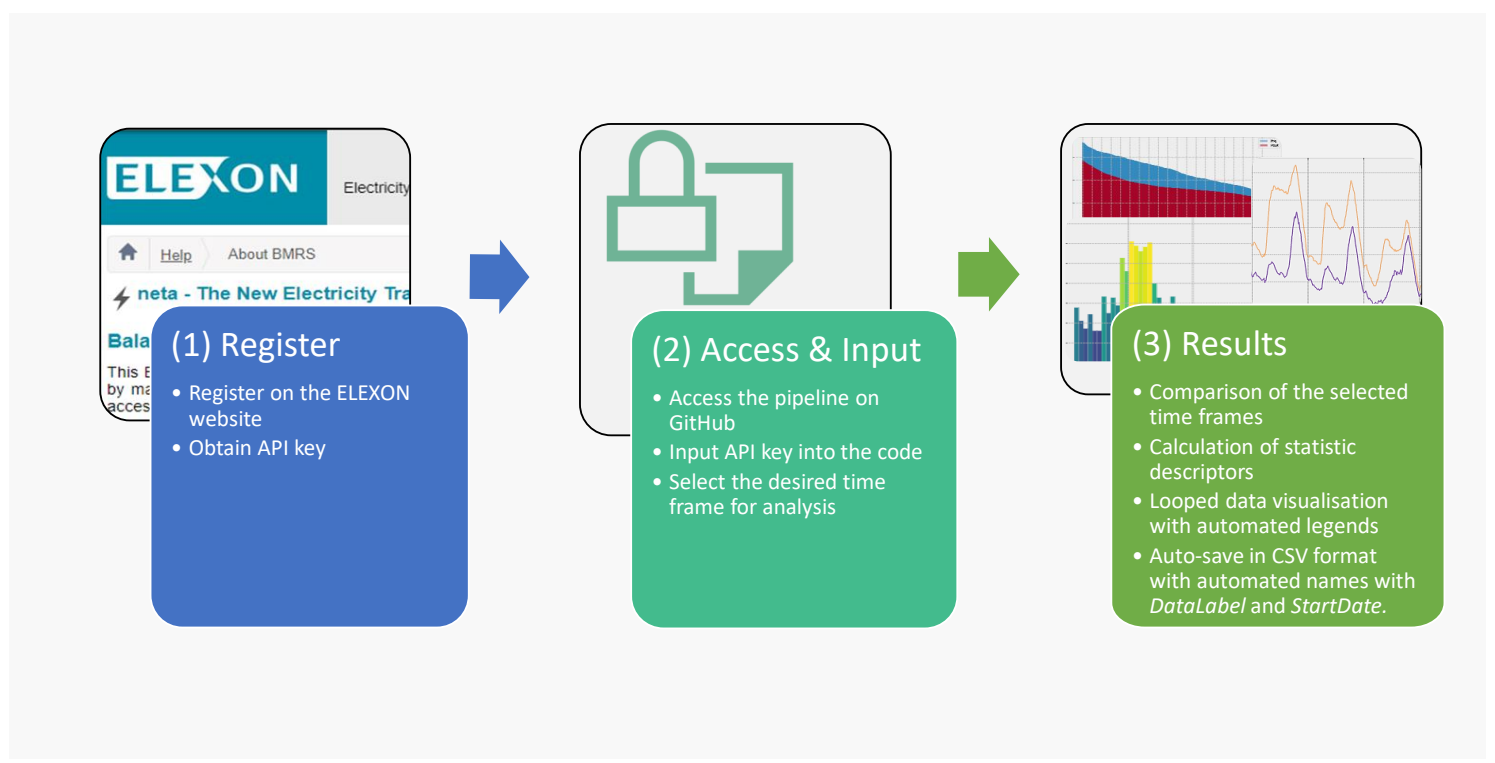

Figure 1. The flowchart displaying the steps for employing the data pipeline which are registering, accessing the code repository and producing the results in order.

As shown in Figure 1, there are two prior steps to reaching the results stage where the quantitative data descriptors are calculated and the results are visualised in a comparative manner. The first step is to obtain an API key by registering on the Elexon website [11]-a more detailed guidance on this is provided by Elexon [10]. Then, the pipeline can be accessed from the GitHub website [8] and the API key obtained by the user should be input. The default timeframes are set to the pre- and post-lockdown weeks used for this analysis which commence on the 2nd and 23rd of March 2020. However, these can be adjusted to the timeframe of interest. In addition to the system demand, this pipeline can be used for all other data types provided by Elexon which are listed in [10]. The code can also be modified to refer to any other website to execute a direct data extraction using API.

\section{Results}

In order to effectively present the impact of the COVID-19 lockdown on the GB electricity system, four main categories are identified and analysed: (1) the changes in demand profile and volume, (2) generation portfolio; renewable and conventional generation shares, 
(3) forecasting and grid stability indicators and lastly (4) market prices, including dayahead wholesale market, system imbalance and variable prices for the domestic consumers. Furthermore, the grid stability subsection inspects imbalance volume, system frequency and the loss of load probability.

\subsection{Demand Profile}

This subsection analyses and quantifies the changes in the electricity consumption caused by the COVID-19 mitigation actions such as the lockdown. On the 23rd of March 2020, the UK Government recommended WFH and closed public spaces such as pubs, restaurants and sport facilities [12]. The impact on the electricity demand is shown by the purple profile and compared to a pre-lockdown week in Figure 2. The figure illustrates that the overall demand decreased as majority of the commercial users (e.g., factories, businesses, etc.) shut down. In addition to the demand reduction, the lockdown also influenced the consumption pattern which results in a changed load profile shape.

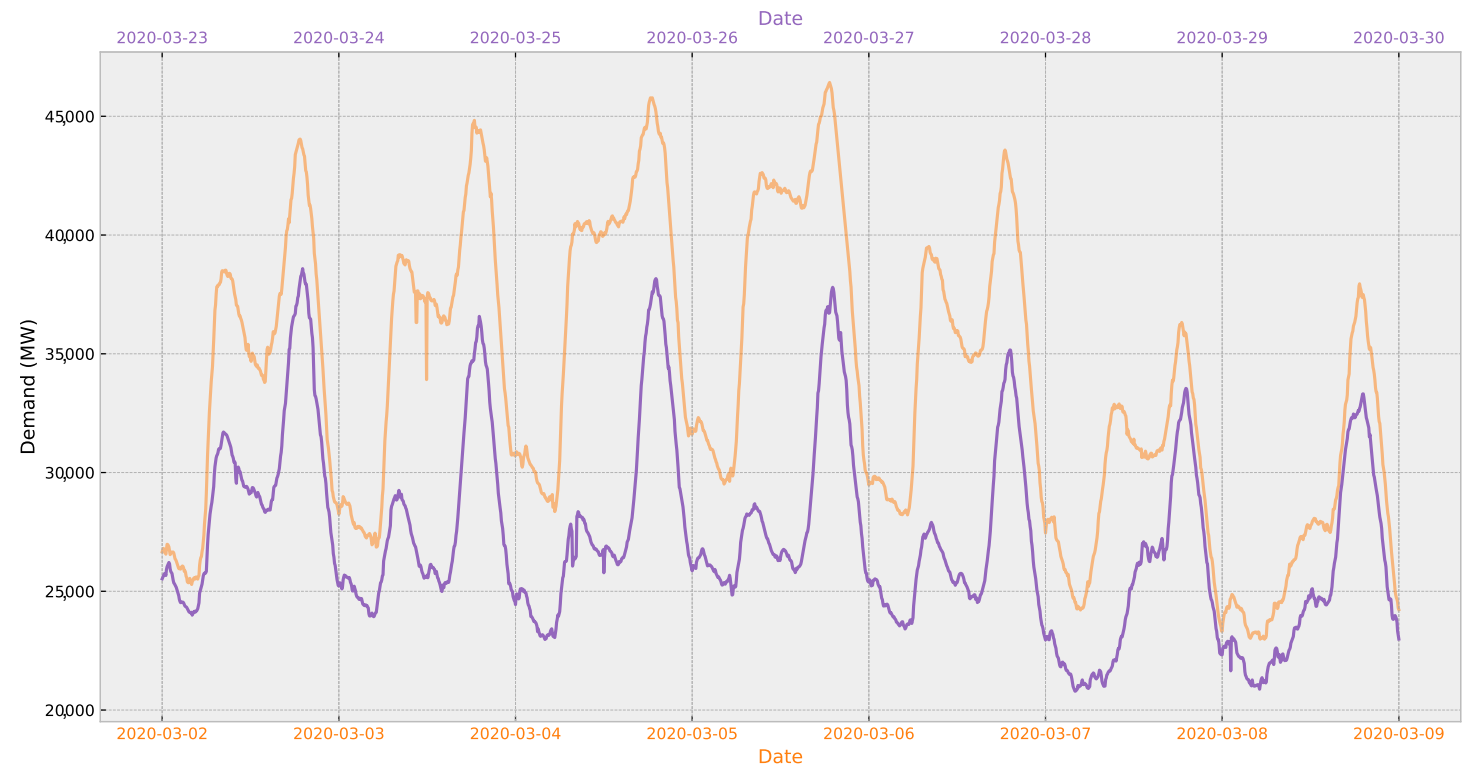

Figure 2. Aggregated system demand before (w/c 02/03/20) and after (w/c 23/03/20) the coronavirus 2019 (COVID-19) actions. Changes are observed in demand magnitude and profile with decreased demand after the lockdown.

Before assessing the impact of the lockdown on the power demand profile, it is important to quantify any change that was caused by any other external variables. The most important factor affecting the power demand in GB is the weather, as it is highly correlated with the energy demand for heating. In order to assess the weather-related impact, the average temperature in Britain is compared for pre- and post-lockdown days. The daily GB average temperature is provided by National Grid which uses data from six weather stations around Britain [13]. Figure 3 shows the temperature difference with an average value of $2.2^{\circ} \mathrm{C}$. According to Thornton et al. [14], $1^{\circ} \mathrm{C}$ difference in temperature results in approximately $1 \%$ change in the electricity consumption. Thus, the weather-related impact is expected to reduce the consumption in the post-lockdown week by $2.2 \%$ when compared with the pre-lockdown week. The maximum temperature difference of $4.2{ }^{\circ} \mathrm{C}$ occurs between the 5th and 26th of March which would decrease the post-lockdown demand by $4 \%$. 


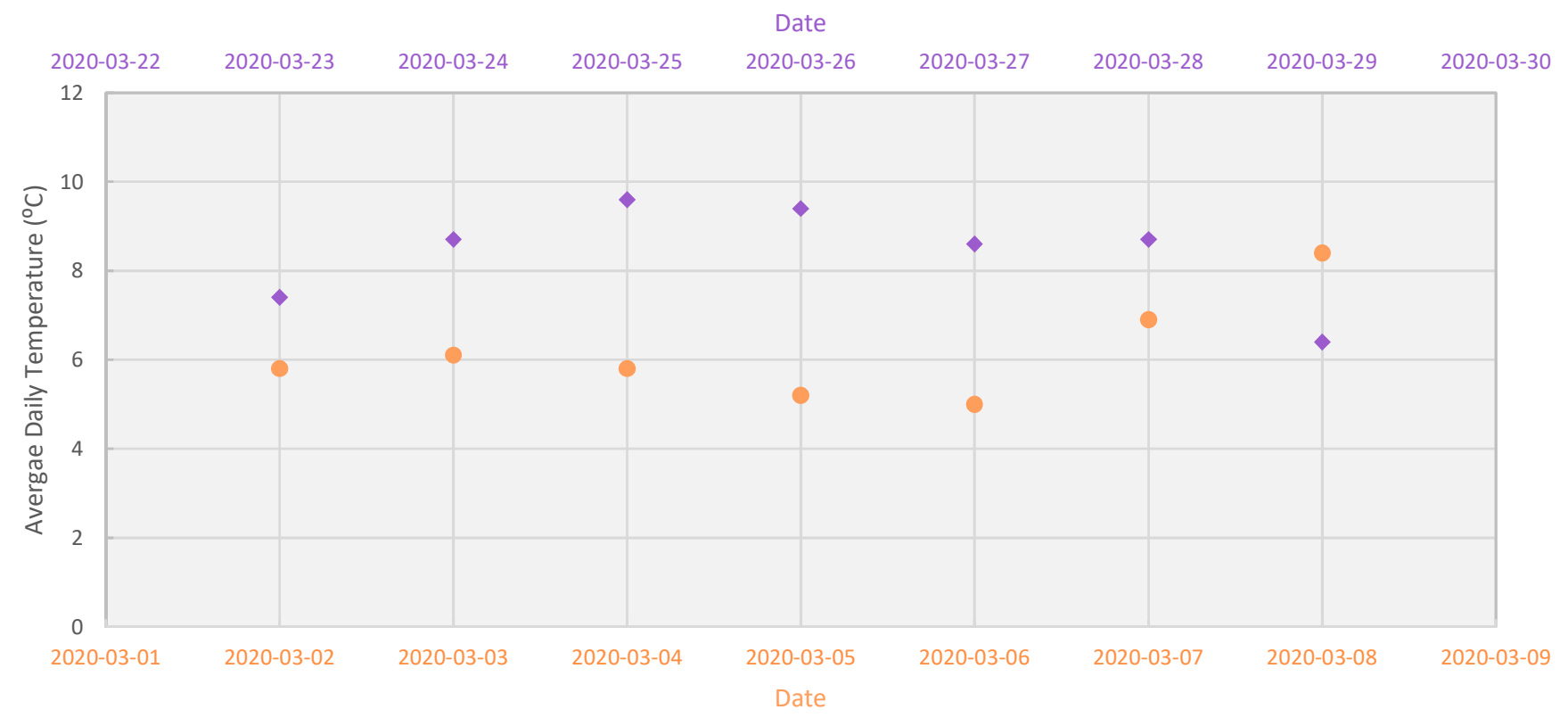

Figure 3. Average temperature data in Britain for before (w/c 02/03/20) and after (w/c 23/03/20) the lockdown. The average difference between the pre- and post-lockdown weeks is $2.2{ }^{\circ} \mathrm{C}$.

As displayed in Figure 4, load duration curves show the base and peak demand by visualising the relationship between sorted demand (i.e., ranked descending) and exceedence. Whilst the base demand decreases by $10 \%$, the peak and mean demand drastically drop by $20 \%$ and $24 \%$, respectively, following the start of the lockdown. As the experienced decrease of power demand is an order of magnitude higher than what would be expected to be due to temperature alone, it can be concluded that the change in demand is predominantly driven by the lockdown rather than the change in the weather conditions.

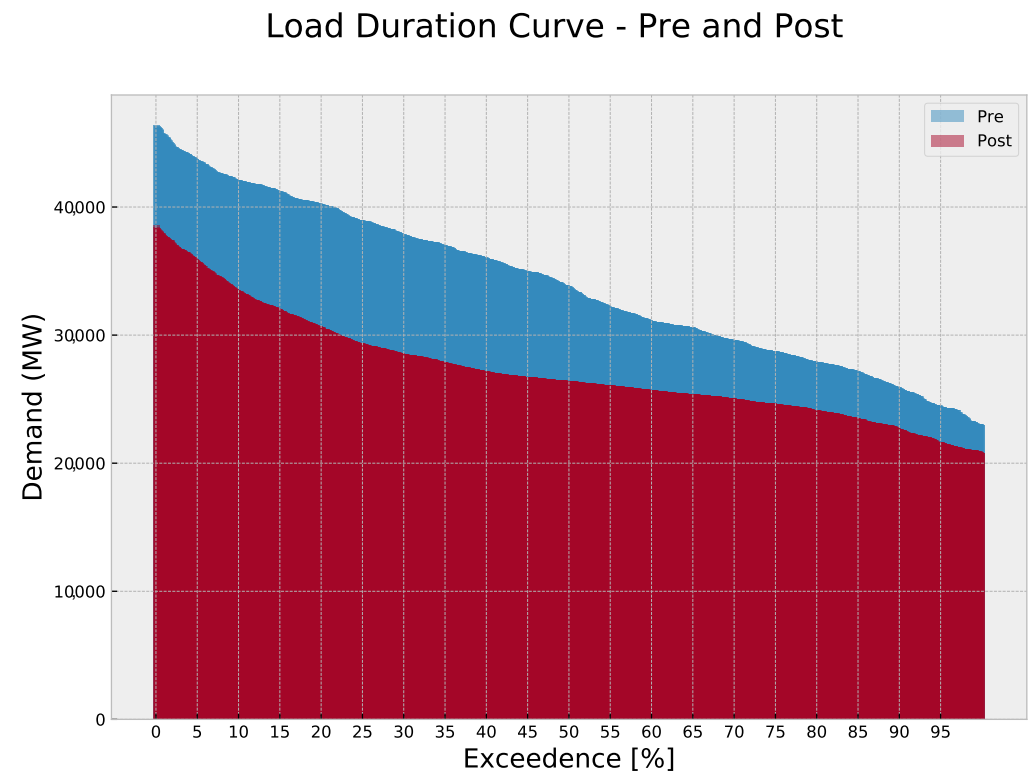

Figure 4. Load duration curve for pre- and post-lockdown actions (w/c 02/03/20 and 23/03/20) showing the decrease in the post-action scenario with the highest decrease in peak and lowest in the base load. 
The changes in the demand profile for peak, mean and base load are shown in Table 1. The decrease in the energy demand is also observed as the area of the red plot (i.e., postlockdown) is smaller than the blue plot (i.e., post-lockdown) in Figure 4. A constant demand would result in a flat load duration curve. This is evident in Figure 4, where the post-lockdown plot (in red) is flatter than the one before the lockdown. This is a result of the greater decrease in peak values in comparison to the base. Flattening the demand curve means the prime time peaks such as the morning pick-up and the evening demand surge are now less pronounced. Such peaks increase the difficulty of matching demand and supply, puts the grid under stress and also increases the stress on thermal generation and storage to meet the demand. The ripple effects include congestion and high imbalance and transmission charges.

Table 1. Changes in demand profile using the data from the load duration curves.

\begin{tabular}{ccccccc}
\hline Profile & $\begin{array}{c}\text { Peak Load } \\
\text { (MW) }\end{array}$ & \% & $\begin{array}{c}\text { Mean Load } \\
\text { (MW) }\end{array}$ & \% & $\begin{array}{c}\text { Base Load } \\
\text { (MW) }\end{array}$ & $\%$ \\
\hline Pre & 46,425 & & 33,868 & & 22,982 & \\
Post & 38,585 & $-20.31 \%$ & 27,294 & $-24.08 \%$ & 20,795 & $-9.5 \%$ \\
\hline
\end{tabular}

Figure 5 displays the pre- and post-demand histograms where the post-action demand is shifted to the left, indicating lower loads. The peak for the post-action demand shows that the range of the most frequently occurring demand values is now narrower, meaning there is less variation. Otherwise, the pre-action demand shows a more dispersed profile with a bi-modal distribution. The concentration and higher rate of occurrence around 26,000 MW also reflect that the time series of demand is flatter.
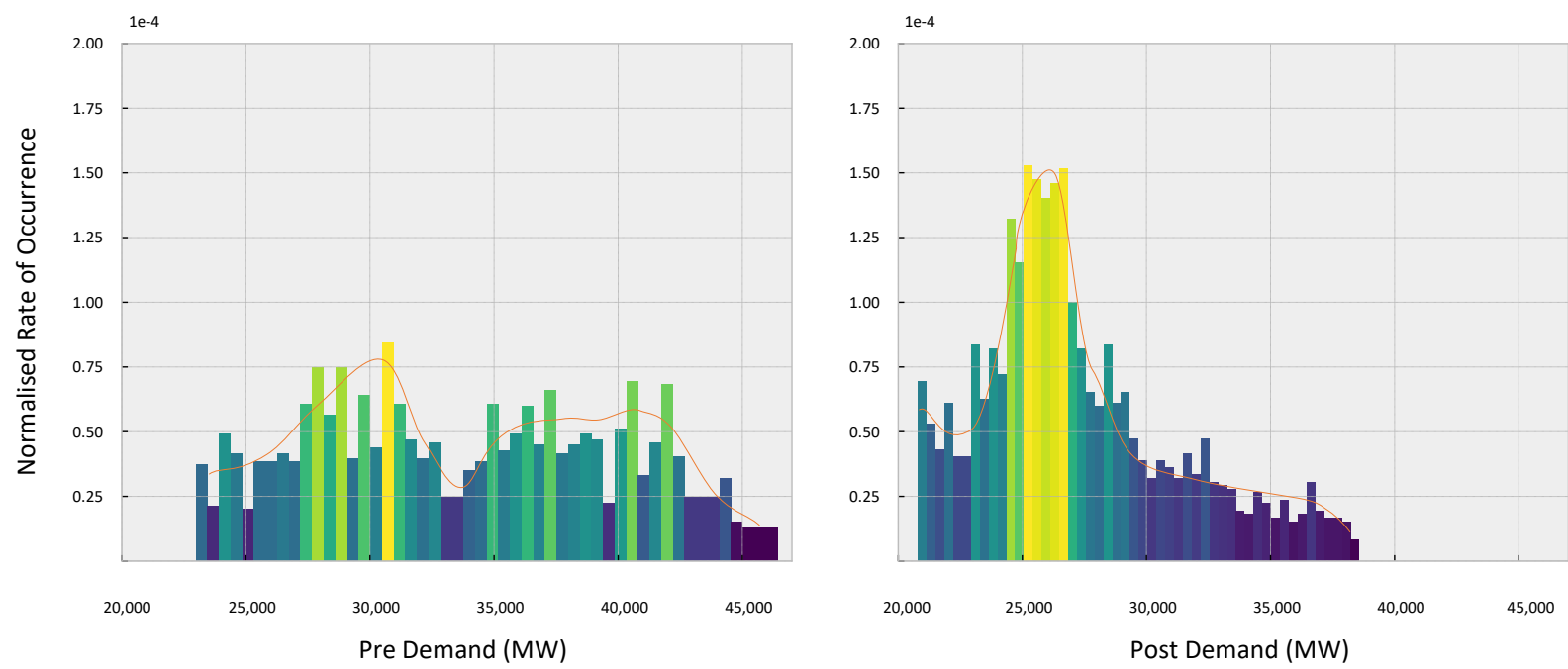

Figure 5. Comparison of pre and post-lockdown demand histograms with normalised occurrences. The range of colours from yellow to dark blue correspond to the highest and lowest values. The post-lockdown shape is smoother and occurrence concentrates only once around $26 \mathrm{MW}$. Whereas, the pre-lockdown distribution has multiple modes as shown by the running average curve in orange. The plot on the left represents $\mathrm{w} / \mathrm{c} 02 / 03 / 20$ and the one on the right represents $\mathrm{w} / \mathrm{c}$ 23/03/20.

Figure 6 uses a ratio of the standard deviation over the mean in order to quantify the variation in the consumption profile. It suggests an overall lower variation in the post-COVID-19 profile with a largest variation in the morning with respect to the mean. The evening variation coefficient is remarkably lower. The overall standard deviation of the post-lockdown week is a third of the pre-lockdown week. Hence, it supports the observation that the post-lockdown demand profile is flatter. Figure 6 reflects an hour 
delay in the morning peak (i.e., 8 to 9 a.m.) and a changed evening profile. Regarding the evening demand surge, it should also be noted that Figure 2 shows steeper evening peaks as the morning peaks become less pronounced for the lockdown week. For instance, on average the pre demand used to have a $7500 \mathrm{MW}$ increase over $4 \mathrm{~h}$ to the evening peak whereas the post-action demand escalates by $9500 \mathrm{MW}$ in $5 \mathrm{~h}$. Despite the longer increase time, the relative increase is higher.
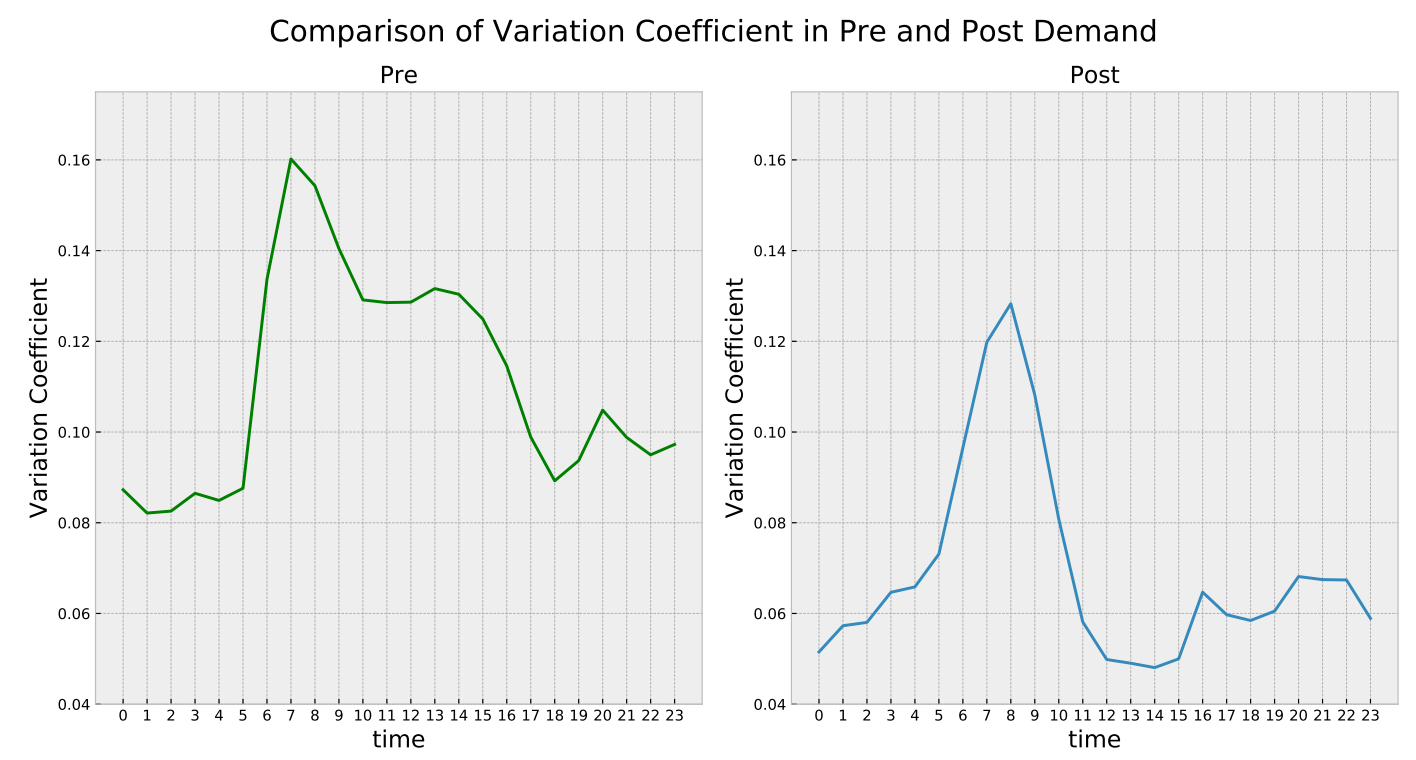

Figure 6. Comparison of variation coefficient to visualise the changes in system demand. The magnitude of the variation coefficient decreases in the post-case, the morning peak is delayed by an hour and the variation in the evening peak is less pronounced. The plot on the left represents $\mathrm{w} / \mathrm{c} 02 / 03 / 20$ and the one on the right represents w/c 23/03/20.

It could be speculated that this is due to the human behaviour change as the common 9 a.m. to 5 p.m. working routine may not apply to all WFH. Hence, the delay in the morning peak may suggest a later wake-up time and earlier pick-up in the evening may be associated with the increased demand for heating, cooking and similar.

\subsection{Generation Portfolio}

This subsection focuses on how the changes in demand pattern and magnitude affected the generation portfolio. In particular, the lower demand led to a higher share of renewable energy sources (RES), namely wind and solar and consequently impacted the conventional generation portfolio in the power system.

\subsubsection{Renewable Energy Contribution}

The share of generation from RES increased following the COVID-19 mitigation actions and consecutive changes in the electricity demand: generators in European electricity markets are scheduled in merit order, which means that the generators with the lowest marginal costs are supplying the power demand. RES generators in particular have marginal costs close to zero. Hence, they are usually scheduled before other generation technologies [10]. Therefore, their output is not restricted by the pandemic circumstances and the changes in the demand profile and magnitude result in the increase of the RES contribution.

On the other hand, these increasing RES shares cannot be easily detected by observed data as they additionally depend on weather conditions. Changing weather conditions make it challenging to compare pre- and post-lockdown data sets as it is not possible to decouple the effect of weather conditions and RES generation. This is because the aggregated RES output from various locations is used for this study. Therefore, Figure 7 illustrates a qualitative example which keeps the RES generated output stable (i.e., unaffected by varying weather conditions), representing constant solar and wind conditions for a high 
and low demand case, respectively. The scale for demand and generation in Figure 7, represents approximately real observed data from GB. In the example, the demand reduction of $25 \%$, which was recognised in the first week after the lockdown, led to an absolute RES share growth of $8 \%$.

As a result of Figure 7 and the requirement of scheduling RES before conventional generators, the average demand reduction leads to higher RES shares in the long term. If the data from Figure 7 are representative for longer periods, they further indicate that the RES share could increase in the range of $5-10 \%$ in the GB system due to the lower demand profile.

\section{Impact of demand changes on the RES share}

\section{High demand case $\quad$ Low demand case}
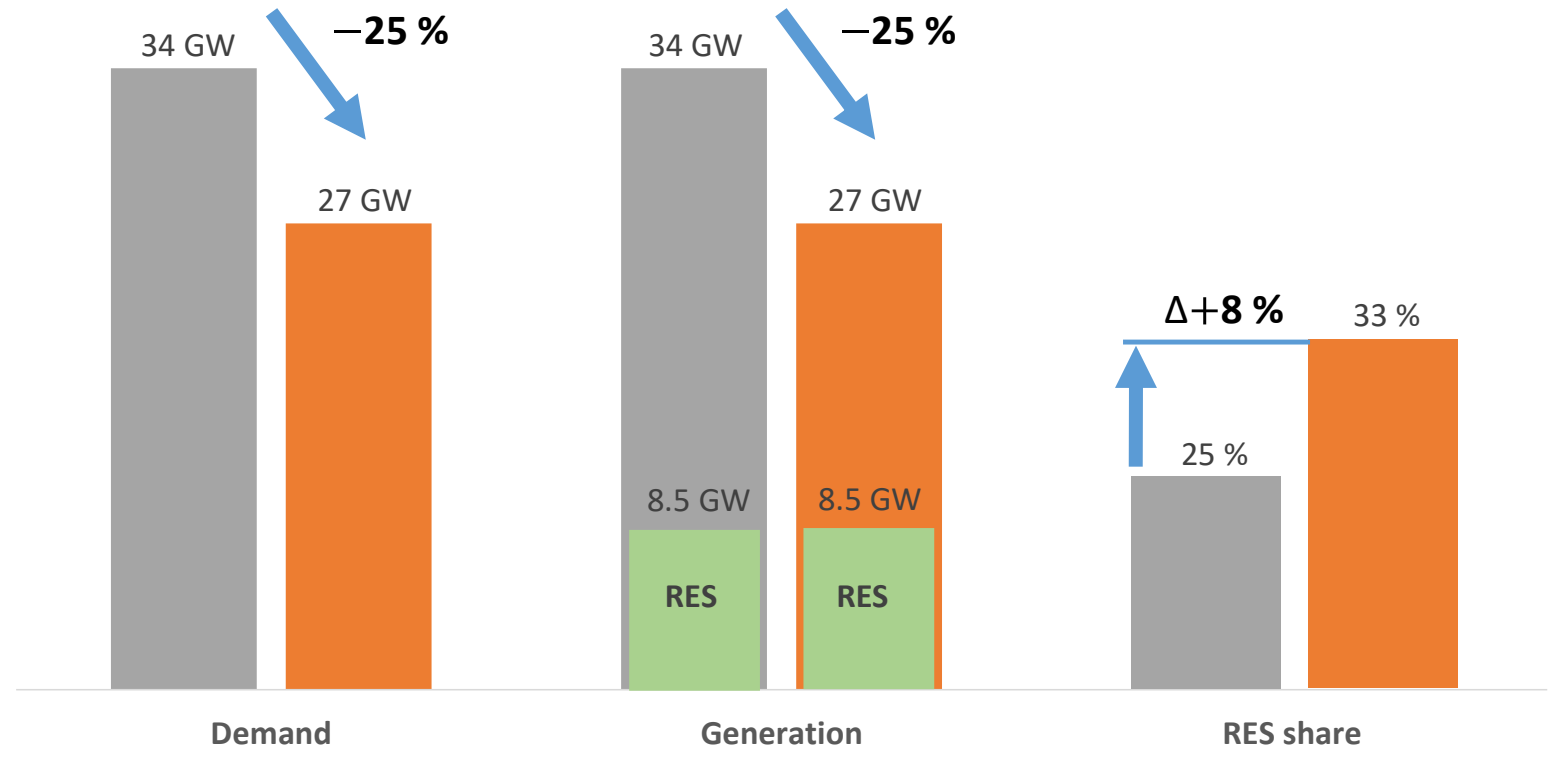

Figure 7. An illustrative example of the impact of demand changes on the renewable energy sources (RES) share for typical UK RES conditions. The RES share grows under the assumption of constant RES output before and after the demand changes. The RES shares are kept constant in order to point out the impact of a lockdown.

\subsubsection{Impact on the Conventional Generation Portfolio}

The conventional generation portfolio, including all generation assets with marginal cost above solar and wind technologies, are expected to decrease in operation time compared to the business-as-usual case. The reason is beside the lower total demand, the higher share of RES assets on the market which are dispatched first because of the merit order. The decrease in operation time particularly affects the higher marginal cost generators such that nuclear and hydro plants are less affected. However, the higher share of RES assets causes an additional need for more flexibility in the power system-similar to the one provided by the natural gas plants [15]. If the inflexible generators sustain their behaviour of not turning down their generation at high RES times, there will be more events when the price is negative [16,17]. Therefore, a flexible gas or biomass plant could be preferred over a less flexible coal plant.

As result, the total generation portfolio is likely to reduce carbon emissions by the increase of the RES share and the push out of inflexible coal plants. 


\subsection{Forecasting and Grid Stability}

The aspects related to forecasting and grid stability are discussed in this section. These include factors such as the deviations in system frequency, imbalance volume and load forecast error of the system operator. Additionally, it investigates the loss of load probability as indicators of the reserve scarcity and increased stress in the grid.

\subsubsection{Deviations in System Frequency}

The system frequency varies continuously and reflects the real-time discrepancies between system demand and total generation. Frequency increases when there is too much generation or too little demand on the system and vice versa. Similar to other system operators, National Grid has a legal obligation to maintain system frequency within the range of 49.5 and $50.5 \mathrm{~Hz}$ [11]. This requires the system operators to accurately forecast demand and schedule generation accordingly whilst keeping a fast-response reserve or a demand-side action available for any unforeseen changes. Nonetheless, the changes in frequency are also related to the system inertia. Introduction of most RES generators such as solar panels and some types of storage such as batteries resulted in a decreased system inertia and consequently a less stable system frequency [18]. Demand-side response (DSR) and other balancing services can be activated to ensure operation within the permitted ranges of frequency [19]. Currently, there is research assessing whether the wind and solar power plants could deploy synthetic inertia in order to compensate for this problem associated with RES generation [20-22].

An abrupt change in the demand, like the one due to the lockdown, is expected to negatively affect the frequency. In this case, the frequency is expected to rise as the decrease in demand would result in a surplus of generation. When analysed in its barest form, no significant discrepancies are observed for a pre- and post-lockdown week. The mean, minimum and maximum frequency values also conclude an insignificant difference below $0.2 \%$ difference-see Table 2. Despite the fact that both the minimum and maximum frequency values for the post-action week are higher than the pre-action week, the analysis is not sufficient to state a remarkable frequency variation due to the lockdown or perhaps more likely that it shows that the frequency was maintained well by the National Grid.

Table 2. Comparison of descriptors to quantify the changes in the system frequency pre- and postlockdown mitigation actions. The increase in the post-action minimum and maximum frequency is highlighted by the red text colour.

\begin{tabular}{cccc}
\hline Data & Mean & Min & Max \\
\hline Pre $(\mathrm{Hz})$ & 49.998804 & 49.736000 & 50.207000 \\
Post $(\mathrm{Hz})$ & 49.998657 & 49.775000 & 50.267000 \\
\hline
\end{tabular}

Hence, a normalised occurrence study is carried out to assess the distribution of system frequency in Figure 8. The distribution for the post-action data has more defined peak around $50 \mathrm{~Hz}$ and its distribution width from 49.9 to $50.1 \mathrm{~Hz}$ is narrower. This suggests that the frequency was maintained within a stricter window than the pre-action week. The concentration of occurrence is below $50 \mathrm{~Hz}$ pre-lockdown whilst values above the nominal values are recorded more frequently after the lockdown (where the range of colours from yellow to dark blue in Figure 8 represents the highest to lowest occurrence, respectively). Hence, this displays a shift in the system frequency distribution, pointing out the increase in high frequency records. 


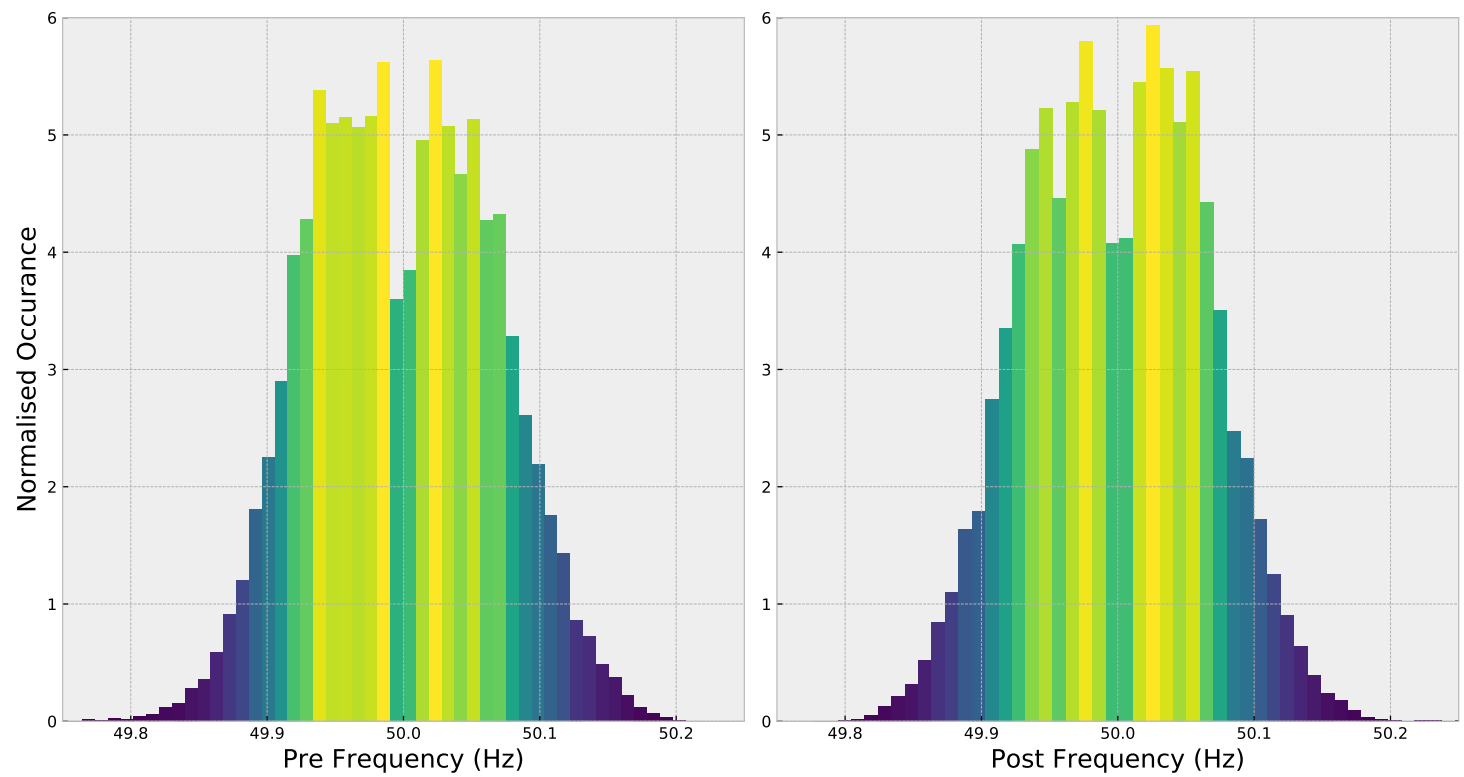

Figure 8. Comparison of pre- and post-action system frequency histograms. The plot on the left represents w/c 02/03/20 and the one on the right represents $\mathrm{w} / \mathrm{c} 23 / 03 / 20$. The post-action frequency distribution is concentrated more in the range of 49.9 to $50.1 \mathrm{~Hz}$.

One reason for this may be the decreased load profile, resulting a generation surplus, thus increasing the frequency-as discussed in Section 3.1. A peak-to-mean analysis is performed on both pre- and post-action data to compare the degree of variation-as shown in Figure 9. The frequency data is indexed by the time of the day. The most significant observation is regarding the high peak-to-mean ratio calculated for 8 p.m. for the postlockdown week. This may be because of the unforeseen changes in the shape of the consumption profile-this is discussed in Section 3.1.

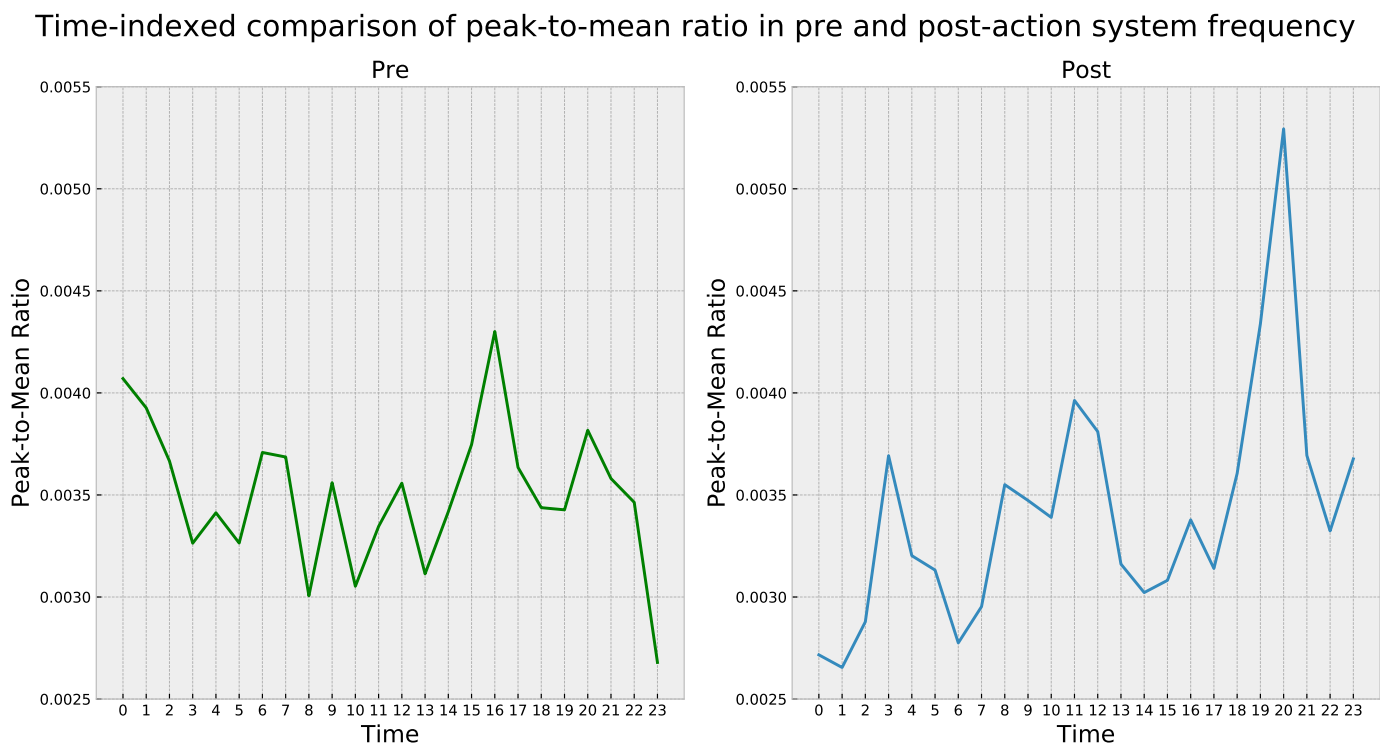

Figure 9. Comparison of hour-indexed peak-to-mean ratios for system frequency, showing an increase in 8 p.m. high frequency occurrence post-lockdown. The plot on the left represents w/c 02/03/20 and the one on the right represents 23/03/20. 


\subsubsection{Load Forecast Error}

The effect of the COVID-19 lockdown on the short-term load forecasts are analysed in the GB power system. In contrast to mid and long-term forecast, which make predictions months and years prior to the event, the short-term load forecasts have a shorter outlook which range from one hour to weeks before the settlement period [23,24]. Short-term load forecasting plays an important role in scheduling the power plants efficiently in the electricity market, as it is essential for economic dispatch and unit commitment [25]. As a result, an improved forecast accuracy leads to a more reliable and affordable power system [23].

Two different short-term load forecasts are analysed in this study, the day-ahead total load forecast (DAF) and transmission system final load forecast (TSF). The DAF and TSF differ in methodology and forecast length. With regards to the methodology, the DAF represents a forecast for the total load in the power system, which equals the sum of generated power on both transmission and distribution networks, whereas TSF is a load forecast which is equal to the sum of generation present on the transmission network. However, this includes generation from pumped hydro storage and embedded large power plants at the distribution network level. Therefore, TSF is interpreted as the net demand, usually published by the TSO for market clearing, while the DAF represents the estimated actual total load in the power system.

Regarding the forecast length, which is the duration from the forecast publication until the operation time, it varies for DAF and TSF, as seen in Figure 10. DAF is published only once a day and predicts the next-day average demand in each settlement period. Hence, the forecast length varies from 12-36 h. Similarly, TSF outputs a day-ahead forecast. However, forecasts for each settlement period are updated until the final TSF which predicts the next average demand in the next settlement period, $1 \mathrm{~h}$ and $15 \mathrm{~min}$ ahead.

\section{DAF and TSF forecast-length}

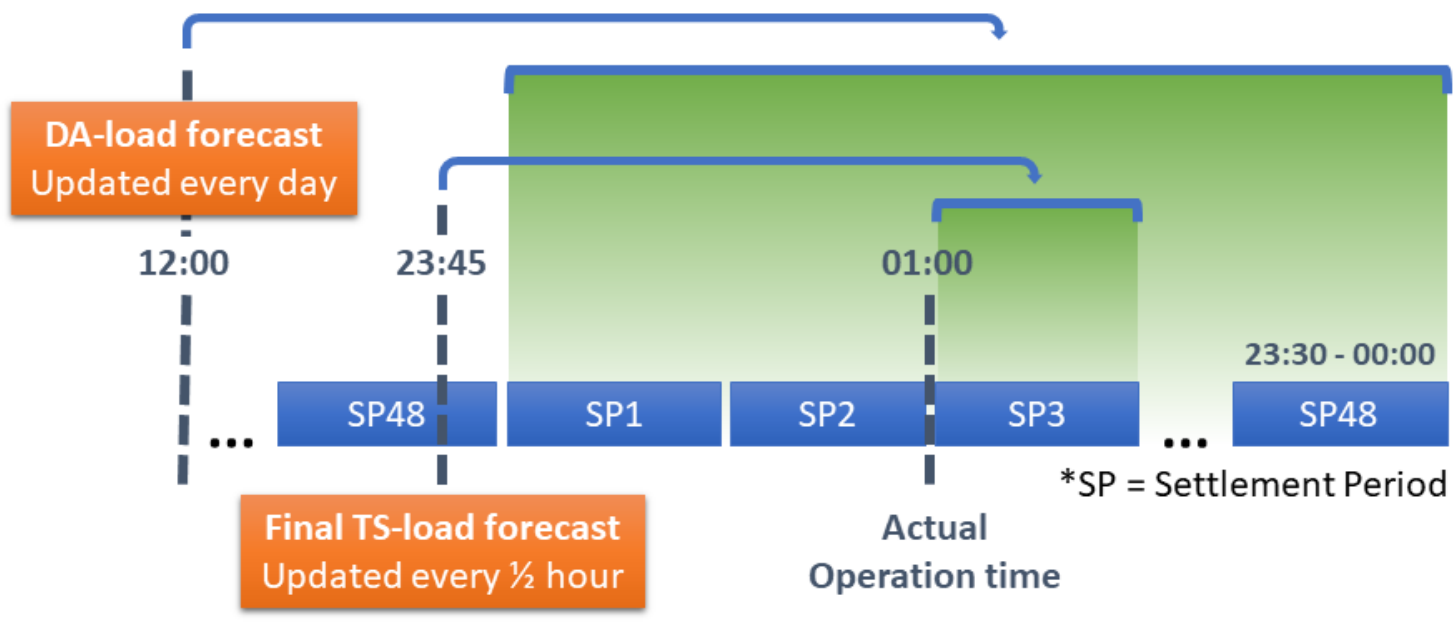

Figure 10. Illustration of the forecast lengths for the total day-ahead load forecast (DAF) and the final transmission system load forecast (TSF).

DAF and TSF forecast errors reveal different characteristics due to the lockdown. The DAF forecast is improved while the TSF forecast does not reflect clear changes. This is shown in Figure 11. The forecast error is evaluated by one of the most common performance indicators, namely the mean absolute percentage error (MAPE) [23,25]. MAPE functions well as a forecast performance indicator when employing historical data. Nevertheless, for prediction model selection and estimation it is biased [26]. As only historical data are analysed in this study, this makes MAPE a suitable indicator. 
MAPE is defined as a summation of forecast errors, where each error is weighted to the actual load. This is shown in Equation (1) where $y$ represents the actual load, $\hat{y}$ is the load forecast and $N$ is the number of forecasts.

$$
\text { MAPE }=\frac{1}{N} \sum_{i=1}^{N} \frac{y_{i, a c t u a l}---\hat{y}_{i, \text { forecast }}}{y_{i, a c t u a l}}
$$

In general, the longer the forecast length is for the same point in time, the higher the forecast error becomes [27].

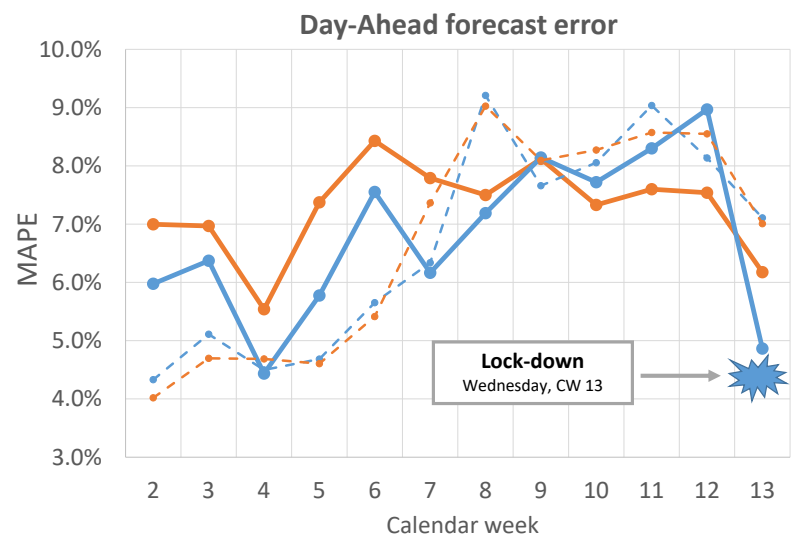

(a) DAF error.

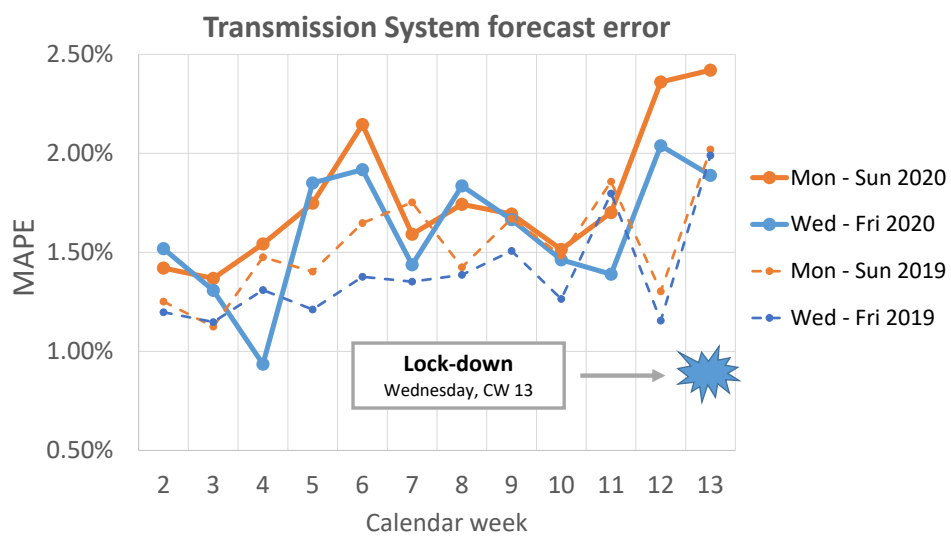

(b) TSF error.

Figure 11. Weekly aggregated total DAF and final TSF error, for the timeframe from (i) Monday to Sunday and (ii) Wednesday to Friday for 2019 and 2020. Note: The Wednesday to Friday frame was used to show the impact of the lockdown from a workday perspective. The lockdown led to a significant improvement of the DAF, while the TSF experience minor changes.

Therefore, the DAF constitutes a higher forecast error than the TSF. With regards to the lockdown effects, the improved forecast accuracy for the DAF is especially remarkable when distilling the timeframe on the weekdays from Wednesday to Friday, which starts on the day the lockdown was initiated. The typical working week differs from the lockdown working week and the weekend is more similar to the lockdown weekend. Hence, the effect of the lockdown would be overlooked if the analysed timeframe was for the whole week. On the contrary, no such effects are observed for TSF, which implies that the shorter-term forecasts are less subject to the lockdown effect.

The change in the forecast error cannot be solely traced back to the lockdown, since the forecast error is affected by many factors. In [27], a list of components affecting the 
forecast errors is given. Nevertheless, in particular, the DAF analysis shows a change of magnitude that could indicate that the lockdown improved the day-ahead forecast. One reason could be the smoother, less variable demand profile which was recognised in Section 3.1. Even though the impact of the TSF change cannot be directly linked to the lockdown due to minimal visible changes, in combination with the imbalance findings in Section 3.3.3, the short-length forecast accuracy evidently decreased.

\subsubsection{Imbalance Volume}

An imbalance is prevalent in the power system when supply does not match demand. If the imbalance is not tackled, it could lead to an unstable frequency and finally blackouts. It is therefore the system operators (SO) responsibility to keep the balance in the system [11]. All accepted balancing measures in a settlement period are given by the net imbalance volume (NIV), which represents the total sum of positive and negative system management and energy balancing measure in the settlement period. In a perfect market, in any settlement period the power plants are scheduled at gate closure (i.e., an hour before the settlement period starts) with a target of NIV close to zero. However, that target is usually not achieved because of:

- Demand prediction errors by suppliers.

- Generation prediction errors by generators (i.e., not able to tightly control the operation of intermittent units).

- Problems in transmission lines.

- Balance must exist at every instant, but market trades in half-hour. settlement periods.

In Section 3.3.2, it is observed that the short-length load forecast accuracy decreased slightly. The consequences of this poorer short-length forecast are amplified in the NIV and cause the NIV to grow significantly compared to all other calendar weeks in 2019 and 2020, as seen in Figure 12. This indicates a change in the amount and volume of balancing measures in the power system.

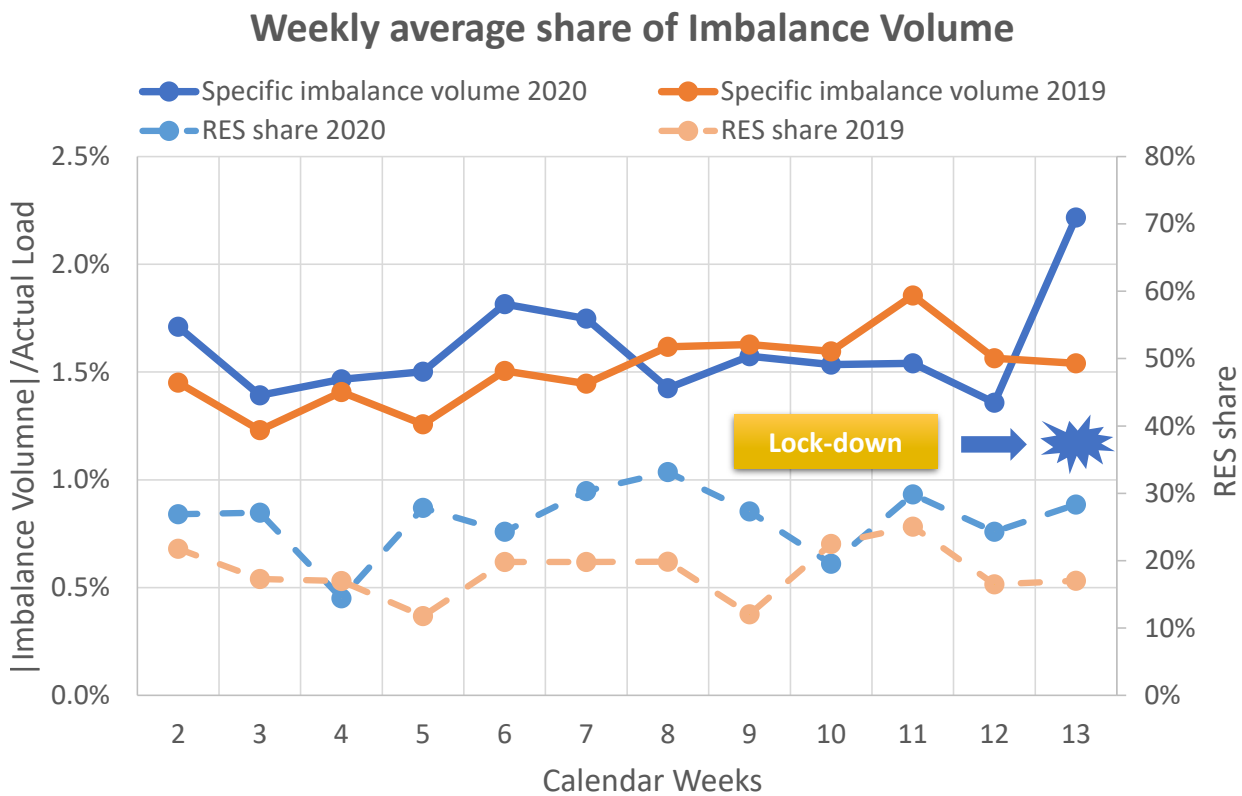

Figure 12. The weekly average share of imbalance volume factorised by the actual total load for 2019 and 2020. There is a significant imbalance increase during lockdown week.

After the lockdown, the higher share of RES seems to be the main driver for the increasing imbalance in the power system. In Figure 13, the imbalance volume was weighted to the actual total system demand for a pre- and post-lockdown week and additionally shows the RES share for the same period. The correlation between weighted 
imbalance volume and the RES share after the lockdown is remarkable which indicates that the increasing RES share is the main driver for the higher imbalance volume. The reason for that cannot be precisely untangled as the following four points can cause an imbalance: generation and demand prediction errors, network constraints and the balance need at every instance. One possible high impact factor could be that the machine learning approaches used by National Grid to forecast embedded RES output and load changes together, had difficulty adapting [28]. However, analysing the past data reveals that the correlation might not be permanent. When analysing data from January to March, only a correlation between RES share and imbalance volume was discovered roughly at $20 \%$ of the time.

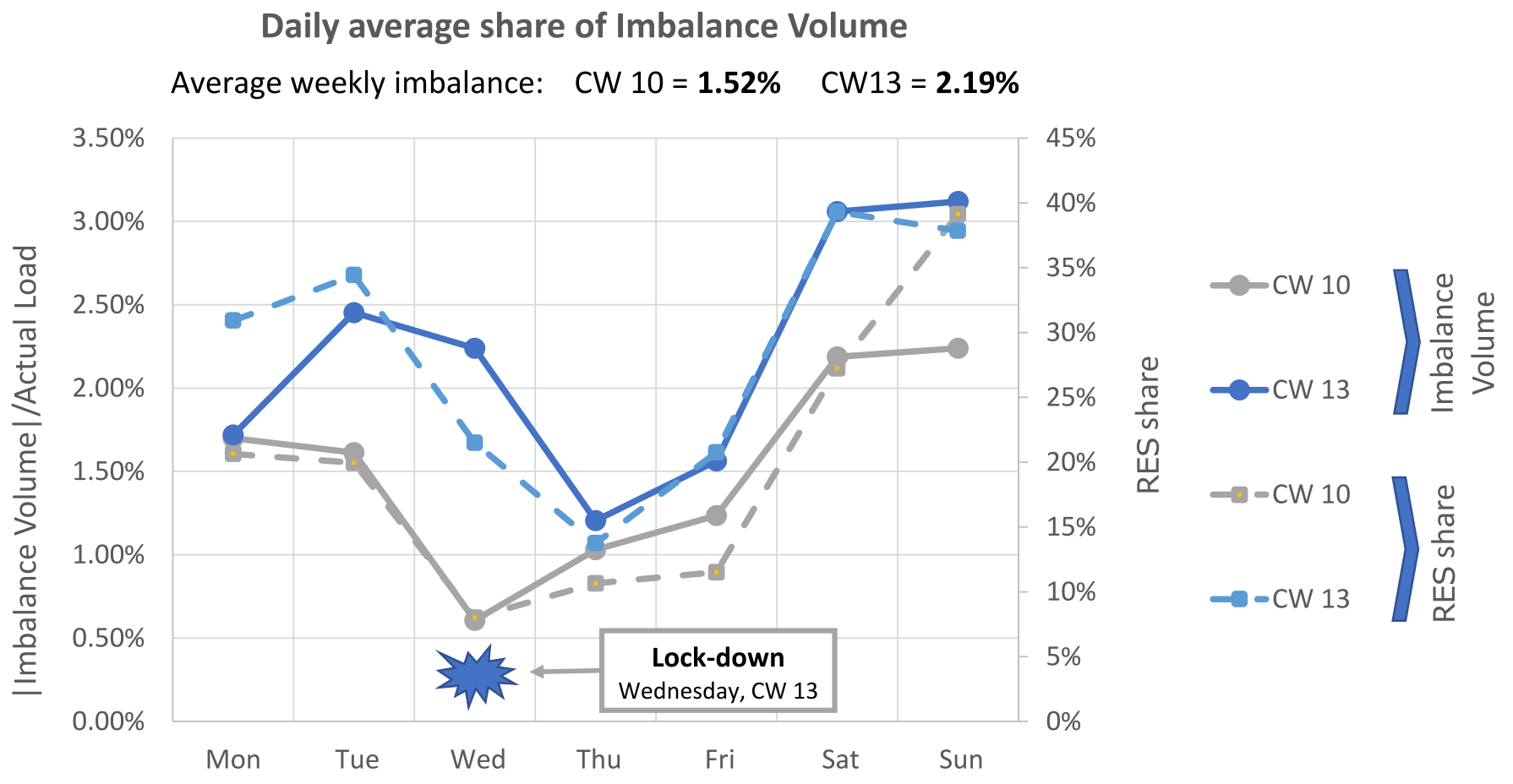

Figure 13. Daily average share of imbalance volume and share of RES for the pre- and post-lockdown week, 2nd-9th March and 22nd-28th March, respectively. There is a strong correlation between the post-lockdown RES share and imbalance volume.

The effect of higher RES shares explains the slightly poorer performance of the shortlength load forecast TSF, as embedded RES, which consisted of 13 GW solar and 6 GW wind capacity in 2018, cause load forecast errors [27,28]. On the contrary, the DAF improved, so there might be a trade-off between the benefit of smoother load profiles and the negative influence of high RES shares on the forecast errors. To summarise, it seems that depending on the forecast length, the lockdown causes improved or worsened load forecast performance (see Figure 14). The short-length load forecasts decrease in performance, while the longer ones increase. 


\section{Illustrative effect of COVID on the forecast accuracy}

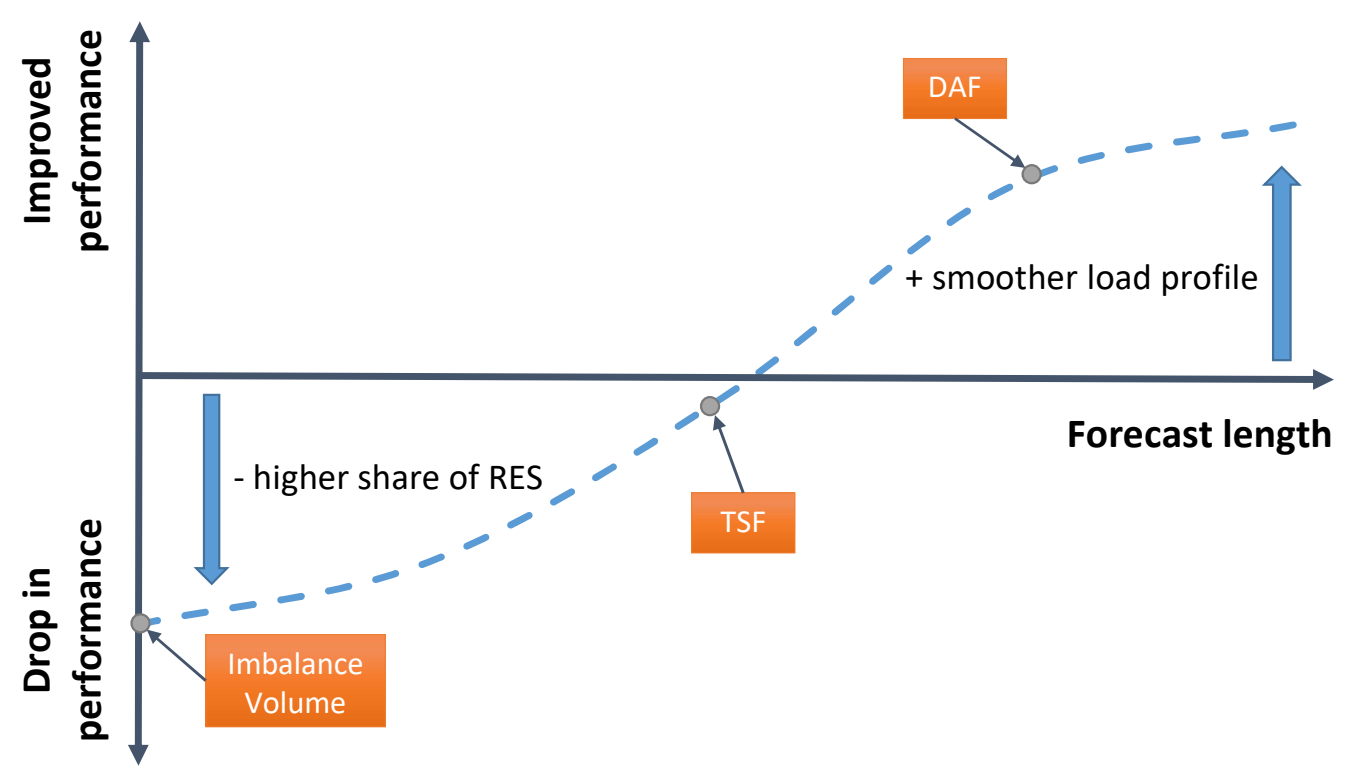

Figure 14. Illustrative effect of the lockdown on the forecast accuracy compared to pre-action weeks. TSF and DAF indicate the transmission system forecast and total day-ahead forecast, respectively, as described in Section 3.3.2.

\subsubsection{Loss of Load Probability}

Loss of load probability (LOLP) is an indicator for system reliability measured by the system operator for each settlement period [29]. For instance, when National Grid predicts higher probability of loss of load, the balancing mechanism is willing to pay higher prices for balancing at the time of reserve scarcity. The methodology to calculate the LOLP can be found in [30]. The higher prices at high LOLP levels are also known as reserve scarcity prices, which are the product of LOLP and the value of lost load (VoLL). The VoLL is determined through the assessment of how much value consumers on average attribute to the security of supply—currently £6000/MWh [29].

$$
\text { Reserve Scarcity Price }=\text { Loss of Load Probability } \times \text { Value of Lost Load }
$$

Due to the abrupt changes in the demand profile and eventually the inflexibility of the available generation, National Grid predicted a higher LOLP during the evening of the 25th of March which was the first official day of lockdown. Despite the fact that it was predicted $12 \mathrm{~h}$ in advance, the hour ahead LOLP forecast was 4.5 times higher. This implies that there was a reserve scarcity and/or that the grid was under stress. On the 4th of March, due to reserve scarcity, the system price increased to $£ 2242$ /MWh in at 17:00 which is the highest recorded value in the last 19 years and almost 20 times higher than the maximum system price in February which was $£ 120 /$ MWh [7].

\subsection{The Effects on Market Price}

\subsubsection{Day-Ahead Wholesale Market Price}

The day-ahead market objective is to define a clearing energy price in which supply meets the demand at any given hour of the day. To do so, a merit order model is used to correctly dispatch power plants by sorting the existing generation units from low to high marginal operating costs. Once the generation meets the demand curve the clearing market price or equilibrium is achieved by minimising the generation cost [31]. Figure 15 shows graphically the process of the merit order model and the location of the clearing 
price as a result of the intersection of the supply and demand curves. The demand is given as net demand which subtracts the RES generation from the total demand. This is a common strategy to illustrate the merit order, since the solar and wind generation plants have marginal cost close to zero, making them always dispatched as long as no network or other operational constraints exist [15].

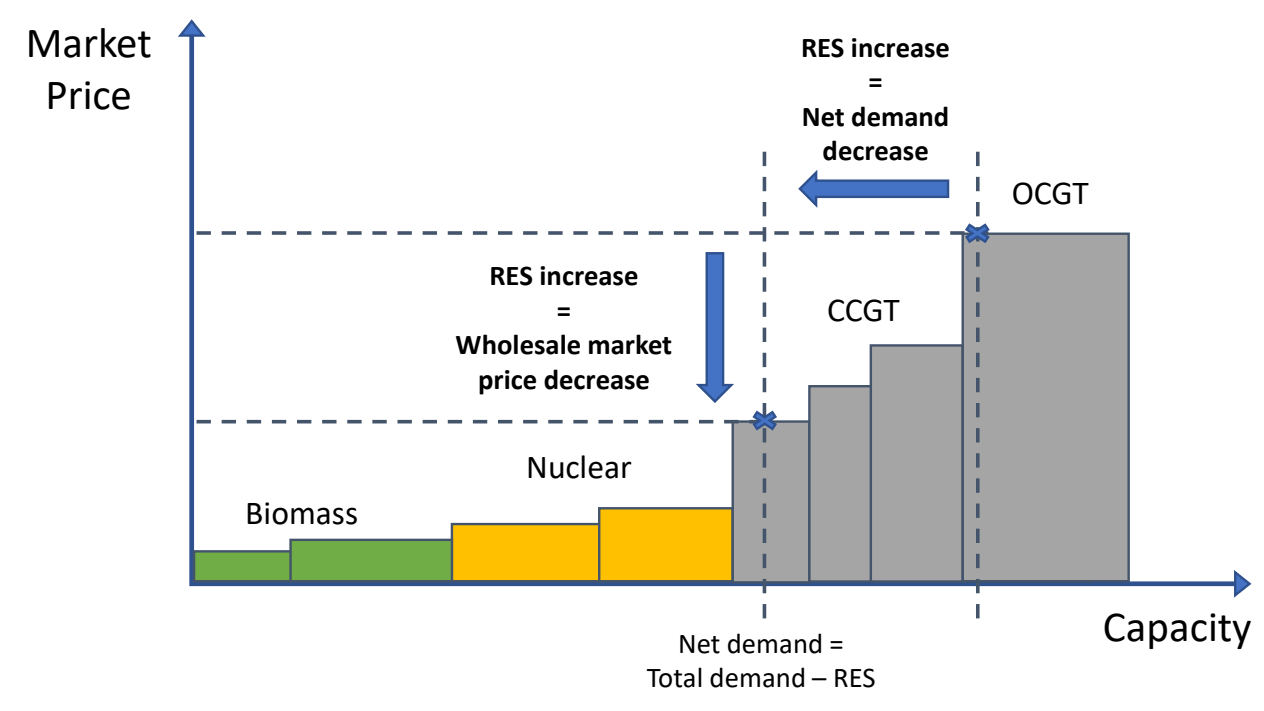

Figure 15. Illustrative effects of the COVID-situation on the wholesale market price. The wholesale market price reduces due to COVID. The higher RES share after the lockdown lowers the net demand which leads to a wholesale market price reduction.

\subsubsection{System Imbalance Price}

The imbalance price is the price set by the system operator for every settlement period to determine imbalance charges on electricity producers (generators) or consumers (suppliers) [29]. The imbalance charge for a settlement period simply consists of the product of imbalance volume (see Section 3.3.3) and imbalance price:

$$
\text { Imbalance charge }_{S P}=\text { Imbalance volume }_{S P} \times \text { Imbalance price }_{S P}
$$

To evaluate the possible impact of the mitigation actions on the imbalance price, it is analysed with regards to its components. The imbalance price is paid for the actions that the system operator initiates to resolve the imbalance. However, the reason for initiating a balancing action can vary. It could be either (i) an energy balancing or (ii) a system balancing action in the 30-minute settlement period [29].

According to [29], the energy balancing action in the balancing mechanism (BM) ensures that the energy amount of the physical notification is achieved. This is usually priced by a bid-offer scheme. The merit-order ranking of the bids and offer is used to reduce the balancing cost as the cheapest units are initiated first. This is not always possible due to technical limitations of generators, demands and networks. An example for a technical limitation of a BM generator is a non-suitable ramp-up rate, or a limitation for the network such as an already congested line which would not allow more generation. Therefore, not only the cheapest BM prices are selected by the system operator. In the BM, units are usually priced by their utilisation cost. The cost of short-term operating reserve (STOR), which can also participate in the BM service, is determined using the reserve scarcity method which is a product of the Loss of Load Probability (LoLP) and Value of Lost Load (VoLL). The resultant charge is the higher of the two pricing outcomes which are namely utilisation price and reserve scarcity price. For instance, when the utilisation price is $10 \mathrm{p} / \mathrm{kWh}$ and the reserve scarcity price is $15 \mathrm{p} / \mathrm{kWh}$, the scarcity price is charged. 
For the purpose of energy balancing, the system operator might additionally purchase non-BM services as the "Balancing Service Adjustment Action" [32]. Drivers for such an adjustment action could be economic, technical or operational for ancillary services according to [19]. These non-BM actions are priced in capacity, energy or both ways and form balancing service adjustment data, consisting of the adjusted buy and sell prices, which adjust the imbalance price of the previously described BM [19,32].

The system balancing actions, otherwise, are only a part of the non-BM actions [19]. They describe balancing actions which keep the energy equilibrium at every instance. For example, a wind power plant might generate the exact energy amount contracted by the physical notification for the 30-minute settlement period; however, its power might fluctuate and mismatch the demand in the settlement period making system balancing actions, such as activation of a non-BM STOR unit, necessary [19]. The pricing scheme for the system balancing actions is equal to the energy balancing scheme for non-BM actions, described in the previous paragraph.

Figure 16 illustrates the weekly average imbalance price development in 2019 and 2020. While both years show similar price variations, a significant price difference exists. This is caused by a regulatory change of the balancing mechanism which started accepting smaller generators in the range between 1-100 MW in 2020 [33,34]. This suppresses the imbalance price through competition. The imbalance price during the lockdown is showing an unclear trend. As described in the above paragraphs, the imbalance price is a complex construct. Due to the substantial changes in the BM in 2019 and 2020, it is not possible to draw a conclusion from this comparison to assess the COVID-19 lockdown effect.

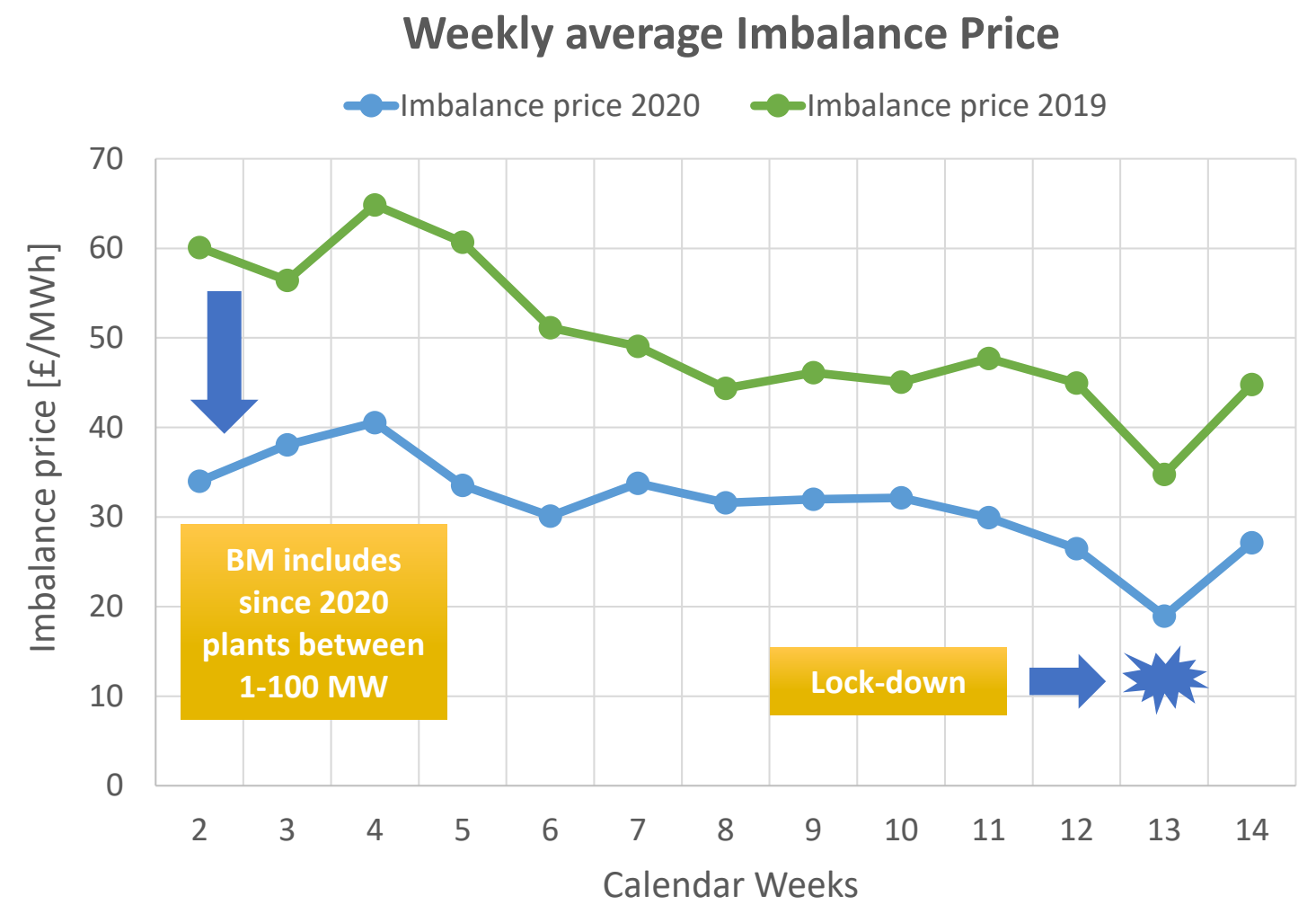

Figure 16. The impact of lower demand on the imbalance price is not clear. Variation and trends observed in both 2019 and 2020 are similar. The observed price difference between the years is caused by wider access to balancing mechanism.

The impacts of the lower demand could potentially both increase and decrease the imbalance price (see Figure 17). The balancing service options are generally chosen following a merit order if no system operation limitation exists. Therefore, similar to the wholesale market price settlement, a higher demand would lead to higher prices and cheaper generators could lower the price or vice versa. The imbalance volume and how it 
can increase the price is explored in Section 3.3.3, which imply a higher need for balancing services. Moreover, on average, a lower demand (as shown in Section 3.1) would potentially free up more generation units that can provide additional cost-effective balancing services. As a result, the imbalance price could increase or decrease. Additional factors also affect the price including the LoLP, VoLL, de-rated margin, voltage-related services and network utilisation.

\section{Potential effects of lower demand on the imbalance price}

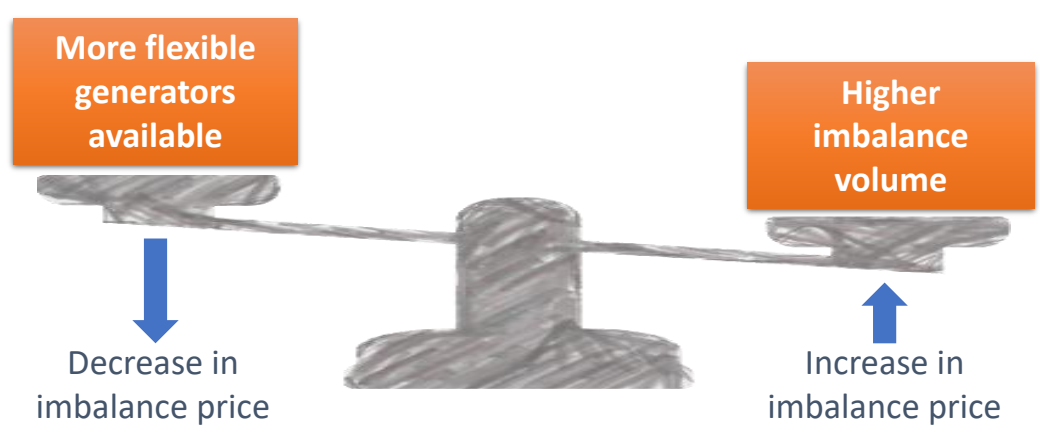

Figure 17. Illustrative example of the impact of lower demand on the imbalance price. Multiple factors impact the imbalance price in different ways. One effect that reduces the imbalance price is that more flexible conventional plants are available due to the lower demand and higher RES share. In contrast, the observed higher imbalance volume increases the price as the more expensive resources must be used (similar to merit order).

\subsubsection{Variable Pricing for Domestic Consumers}

The case for variable pricing for domestic consumers has been made by numerous studies [35]. It is a more consumer-centric approach where the domestic consumers are billed using the same half-hourly prices as the commercial ones rather than having a fixed tariff (i.e., a volumetric calculation using a fixed $£ / \mathrm{kWh}$ rate). There is also the commonly known time-of-use (ToU) pricing where the $£ / \mathrm{kWh}$ rate varies for different times of the day which usually correlates to higher rates for higher demand periods. For instance, electricity prices from 4 to 7 p.m. would be higher to reflect the evening peak whereas from 1 a.m. to 4 a.m. when the demand is usually low, the prices would be lower. Hence, this method of pricing would also result in demand shifting.

British energy supplier Octopus [36] introduced their agile electricity tariff which is an indexed half-hourly dynamic pricing that tracks the wholesale price of electricity (i.e., the domestic rate changes every $30 \mathrm{~min}$ instead of a fixed monthly rate). On different occasions, this resulted in negative pricing (i.e., the energy supplier paid its customers to consume electricity). However, this also means that there is usually a steep price from 4 p.m. to 7 p.m. during the evening consumption surge. The following logic in Equation (3), is used to determine the prime-time pricing. It uses the distribution cost coefficient $(\tau)$ multiplied by the wholesale cost of electricity $(W)$ and $P$ which is the peak-time premium (which is equal to $12 \mathrm{p} / \mathrm{kWh}$ during prime time). Then it caps the price to $£ 35 \mathrm{p} / \mathrm{kWh}$ if the previous outcome is higher than this value. This is because on average the fixed tariffs are in the range of $15-20 \mathrm{p} / \mathrm{kWh}$ and it could be argued exposing domestic consumers to extreme fluctuations in the system would be unfair.

$$
\min ((\tau \times W+P), 35 \mathrm{p} / \mathrm{kWh})
$$

In Figure 18, an example of capping at the maximum price of $35 \mathrm{p} / \mathrm{kWh}$ is shown on the 4 March 2020 (i.e., during the pre-lockdown week). This day marks the first time a system price was over $£ 2000 / \mathrm{MWh}$ since 2001. It peaked at $£ 2242 / \mathrm{MWh}$ [7] 
(See Section 3.3.4 for more information). The week commencing on the 30th of March 2020 is of interest for comparison with the other extreme, namely negative pricing, as it drops to near $-3 \mathrm{p} / \mathrm{kWh}$. Similar to the analysis in Section 3.1, the reduction in demand magnitude and changes in profile are correlated to the changes between pre- and post-action pricing profiles in Figure 18.

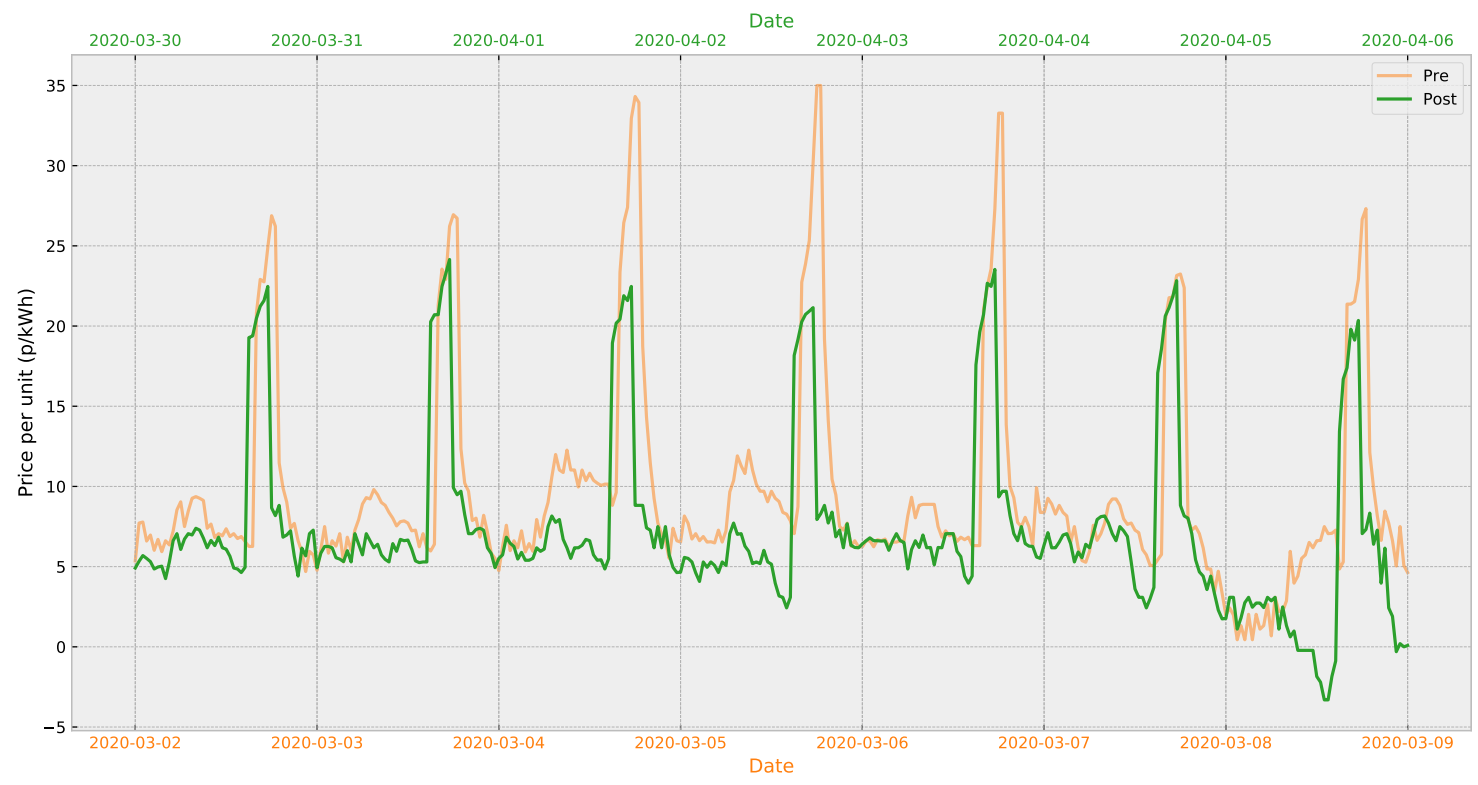

Figure 18. Examples of price capping (5 March 2020 on the lower orange x-axis) and negative pricing (5 April 2020 on the higher green $x$-axis) during pre- and post-lockdown weeks, respectively, using the data from [37].

Since the launch of the agile tariff, there had been 96 occurrences of negative pricing (i.e., price $<0 \mathrm{p} / \mathrm{kWh}$ ). Almost $70 \%$ of these events (i.e., 67 out of 96 ) took place after the lockdown started. Table 3 summarises the negative pricing events before and after the lockdown, highlighting the highest price the consumers were paid to use electricity and the corresponding dates.

Table 3. Analysis of negative pricing in the agile tariff using the data from [37].

\begin{tabular}{ccccc}
\hline Data & Mean & Min & Max & Dates Corresponding to Max Values \\
\hline Pre $(\mathrm{p} / \mathrm{kWh})$ & -1.62 & -0.07 & -4.85 & 9 December 2019 \\
Post $(\mathrm{p} / \mathrm{kWh})$ & -1.36 & -0.02 & -3.99 & 20 April 2020 \\
Overall $(\mathrm{p} / \mathrm{kWh})$ & -1.44 & -0.02 & -4.85 & 9 December 2019 \\
\hline
\end{tabular}

Octopus also provides variable pricing for selling electricity [36]. The corresponding sell prices are plotted in Figure 19. The highest sell price around $19 \mathrm{p} / \mathrm{kWh}$ was recorded which corresponds to the day with the highest system price since 2001 . The benefit is passed on to the distributed generators. In the case of negative load pricing when the consumers were paid to use electricity on the 5th of May, there was also negative pricing for exporting electricity (i.e., generators pay to export electricity). The pricing for generation is capped at a minimum of $0 \mathrm{p} / \mathrm{kWh}$ which indicates that the energy was exported for free during that period as shown in Figure 19. 


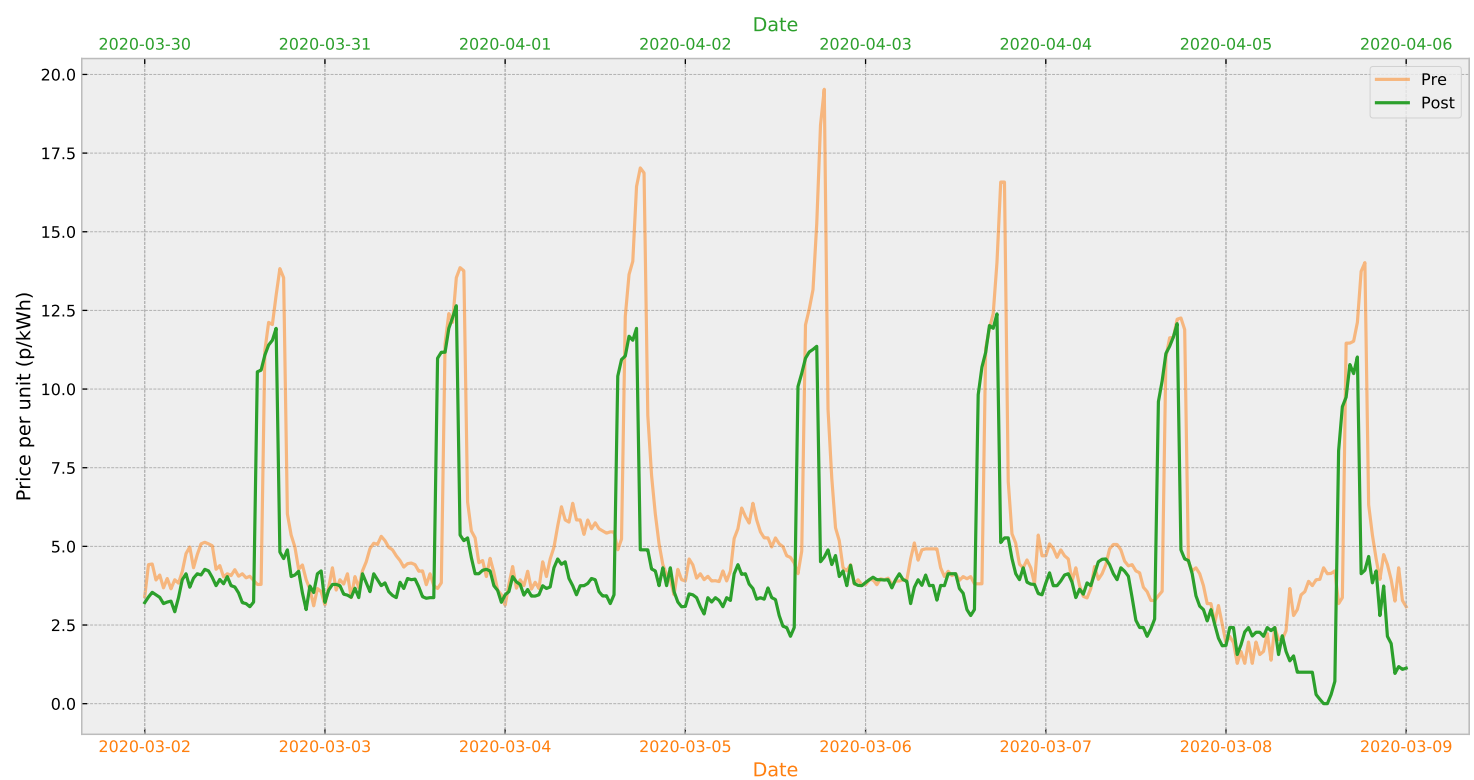

Figure 19. Corresponding agile outgoing sell prices using the data from [37], that show a high sell price reflecting the reserve scarcity (5 March 2020 on the lower orange x-axis) and a capped price of 0p/kWh (5 April 2020 on the higher green $\mathrm{x}$-axis).

\section{Discussion}

In Section 3, four main categories of results were presented, namely: (1) the changes in demand, (2) generation portfolio, (3) forecasting and grid stability and lastly (4) market prices. In this section, these results are evaluated and their impact on different stakeholders are discussed. Following this, the limitations of the results are addressed along with suggestions for future work.

The key results are summarised in Figure 20. They indicate that the grid is still reliable and stable but operates under stress. More detailed explanations of each point here can be found in Section 3.
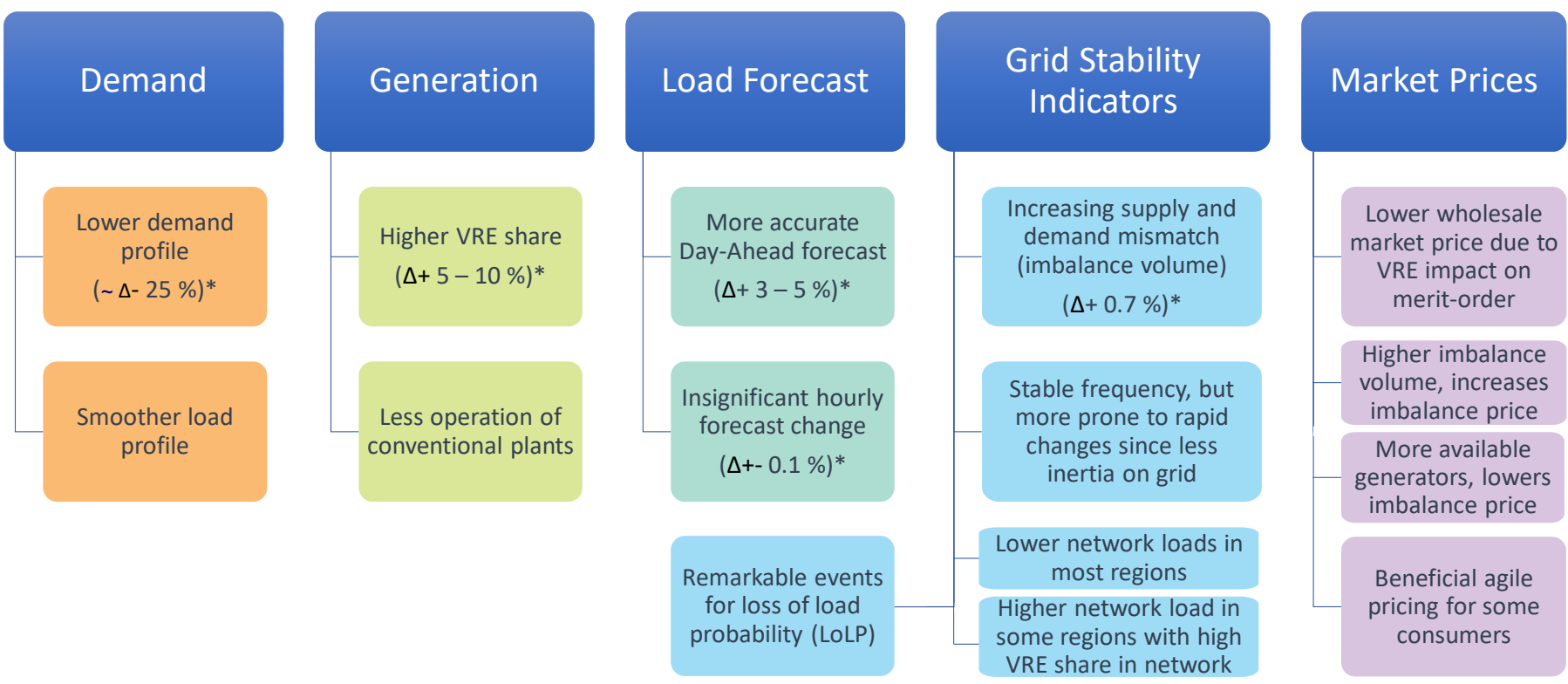

Figure 20. Summary of key results. The asterisk $\left(^{*}\right)$ notes that the effect of some factors such as economic climate were not taken into account. More details on whether these changes are representative are in Section 3. 


\subsection{Implications for Stakeholders}

The new disruptive and lower demand profile has multiple effects on the stakeholders in the electricity system including network operators, suppliers, generators, aggregators, DSR providers and consumers.

The network operators face a lower system demand on average which would result in generally lower loading on the network yet occasionally higher network loads in some cases. Firstly, a higher amount of balancing services are expected due to the decreased performance in short-term forecasting (see Section 3.3.2) and hence, the resulting higher volume of imbalances (see Section 3.3.3). Secondly, lower network loads are expected due to the lower average load during the lockdown. However, at some particularly RES-rich locations the network load may increase due to the increased power flows (see Section 4.1.1).

In the wholesale market, suppliers interact with generators to form long-term electricity supply contracts [29]. The imbalance volume increased due to the lockdown which most probably was unforeseen at the time of the contract. The increasing load uncertainty and changes in the load profile may imply that both of these parties are subjected to more imbalance charges. The trend of the total amount of imbalance charges cannot be easily detected, as described in Section 3.4.2. The imbalance price is a complex measure which can increase and decrease due to the lockdown effects. In addition to the imbalance, generators and suppliers would suffer from the disruptive demand changes in terms of profitability. The share of fixed cost compared to amount of sales may increase to compensate for the lower volume of electricity demanded. This eventually would lead to higher electricity prices for domestic and industrial consumers. On the contrary, suppliers are expected to benefit from lower wholesale market prices. For instance, as the demand decreases, the supplier would need to purchase a smaller volume of energy resulting a lower cost whilst receiving fixed instalments from domestic customers (see Section 3.4.1).

Aggregators and DSR providers are predicted to be scheduled more often by the system operator because of the larger imbalance volume observed during the lockdown. The only requirement for them is to be more competitive than the flexibility offered from the non-scheduled power plants as more plants are expected to be available for such services due to decreased baseline consumption. If so, aggregators and DSR providers would benefit from the COVID-19 lockdown.

There is virtually no benefit for the distributed consumers with a fixed rate supply agreement as the average domestic household demand is expected to increase due to WFH. However, there has been approximately 70 negative pricing events since the lockdown started which suggests that consumers with variable pricing such as the agile tariff are getting paid to use electricity. Such consumers can also take advantage of reserve scarcity and benefit from exporting when the grid is under stress (see Section 3.4.3 for more details). Regarding the commercial and industrial users, the same would apply which indicates that the users with the most flexible assets/loads would be able to take advantage of the effects of the lockdown on the pricing.

\subsubsection{Implications for Future Systems}

The demand and generation findings for the lockdown state of the electricity system can be used as a representation of the next decade according to the International Energy Agency [38]. This would be when the share of RES, such as from solar and wind, is higher and balancing services are more in demand. Therefore, this suggests that the results of this study (see Figure 20) regarding the effect of the lockdown due to the COVID-19 pandemic can be interpreted as an outlook into the future.

As suggested by several indicators, when using the findings of this paper as a future scenario, several assumptions and limitations must be noted. Firstly, the lockdown changed the load profile shape which resulted in a flatter profile that is different than a typical future demand scenario which may assume more efficient home appliances but increase in electric vehicle ownership (i.e., increase in over-night demand). This flatter demand profile, counter-intuitively, led to better day-ahead load forecast even though the share of 
RES increased. Secondly, the current power system is supported by inflexible nuclear and gas plants which might change in the future due to the increasing amount of flexibility services such as DSR. Lastly, the current network is comparatively oversized due to the lower load. The same network at higher RES share could lead to more congestion in a future power system.

One of the most important aspects of planning for a future power system is consideration of network congestion that is expected to occur as RES share increases. During a lockdown, the network usage is expected to decrease on average but some sections might be loaded more than usual. The lower average demand in GB implies that less energy is transported through the power lines which results in reduced network usage and losses. However, loading of some other network sections could increase as centralised renewable energy sources would transport energy for longer distances. For instance, the large wind generation capacity installed in Scotland provides more energy to the southern parts such as London. As the net consumption in GB decreases, less energy is locally consumed in the north and may lead to higher network loads along the transmission lines when there is generation from wind and/or solar. Therefore, despite the decreased load, some parts of the network are likely to experience higher congestion.

For data with high temporal resolution such as frequency and demand, there are many variables that affect long-term (i.e., 2019 vs. 2020) comparison including weather conditions, availability of generators, increase in demand and generation, network management actions, etc. This is a known challenge that has been the subject of previous studies such as [39]. Hence, the long-term comparison is limited to the weekly average values in this study. In terms of short-term comparative analysis (i.e., pre- and post-lockdown days-up to a week), the effect of the weather data such as humidity, temperature and wind speed are not taken into account. This is because the effect of weather conditions and other socio-economic impacts are observed to be less significant in comparison to the effect of this major socio-economic event, namely the lockdown due to the spread of COVID-19 in GB.

\subsection{Outlook and Future Work}

Overall, this analysis reveals a significant point for future models of a low probability but high impact event such as the 2019 pandemic. This is that the imbalance increases and stresses the grid if the operator is not prepared. This has the potential to result in a record high system price (such as the $£ 2,242$ / MWh mentioned previously) and/or a more severe problem such as a blackout in the future power system. The main findings, which are summarised in Figure 20, can be used for modelling the demand, generation, market and grid stability for a future low probability high impact events. Variable pricing for domestic consumers gives price signals that can beneficially change demand profiles. As shown in Section 3.4.3, the lockdown has led to almost 70 events of negative pricing where the users were rewarded for their consumption. At the same time, the distributed generators benefited from some high sell prices during the lockdown. The introduction of half-hourly indexed variable pricing encouraged peak-shaving during high demand periods where prices are expensive and more consumption during energy surplus times where prices are low and sometimes negative. As a consumer-centric innovation, the variable pricing approach can function as a gateway for emergent markets such as peer-to-peer trading which involves the exchange of electricity amongst distributed consumers to increase their self-sufficiency [35] proves that even consumers not participating in DSR actions would benefit from real-time and variable pricing. Using disruptive technologies such as home energy management systems, smart metering and internet of things (IoT) loads can respond to price signal and adjust their scheduling in order to minimise their electricity cost. This is especially significant when charging electric vehicles as discussed in [40]. On the grid scale, studies such as [41] prove the significance of scheduling algorithms for taking advantage of both arbitrage and other DSR events and highlight the future potential of commercial size battery energy storage systems. 
The outcomes of this analysis may be used for predicting the response of the electricity market to another low probability and high impact event in the future.

\section{Conclusions}

The outbreak of COVID-19 disrupted the patterns in electricity consumption, challenging the system operations of forecasting and balancing the supply and demand. This is due to the mitigation measures that include lockdown and WFH which decreased the aggregate demand by $25 \%$ and remarkably flattened its profile. These changes were characterised with various quantitative markers and compared with pre-lockdown business-as-usual data using the case study of Great Britain. Similar observations have been made in different countries such as Australia [42] and Italy [43].

The ripple effects on the generation portfolio revealed a 5 to $10 \%$ higher RES share and decreased operation of conventional plants. The system stability indicators suggest that the grid operated well but was under stress. The indicators include some remarkable LoLP events and overall higher system frequency. However, other contrasting findings show 3 to $5 \%$ more accurate day-ahead load forecasts. The energy market is also greatly affected by the change in consumption pattern. The wholesale market price decreased due to RES generators ranking higher on the merit order. Whilst the imbalance prices increased due to the higher imbalance volume in the system, this increase was compensated by the larger number of available generators due to the decreased demand volume.

An alternative pricing mechanism was also investigated for domestic consumers. With over 70 events of negative pricing, it was shown that the new pricing scheme would have benefited consumers with flexible load such as an EV. Despite the overall drop in the prices due to the decrease in wholesale market price, there were some LoLP events that increased the system price as much as $£ 2242$ /MWh which is the highest in the last 19 years and almost 20 times higher than the month preceding the lockdown (February 2020).

Four main categories of results presented, namely: (1) the changes in demand, (2) generation portfolio, (3) forecasting and grid stability and lastly (4) market prices Section 4 assessed their impact on different stakeholders such as system operators, suppliers and consumers. Following this, the limitations of the results were addressed along with suggestions for future work.

The proposed open-source energy data extraction and pre-processing pipeline can be used in a variety of similar studies-see Figure 1. It can be useful for both academic and industrial research in electricity markets, trades and forecasts as it simplifies the procedures of data extraction, pre-processing and visualisation.

Author Contributions: Conceptualization, D.K., M.P. and A.K.; methodology, D.K.; software, D.K.; validation, D.K., M.P. and A.K.; formal analysis, D.K and M.P.; investigation, D.K. and M.P.; resources, D.K., M.P. and A.K.; data curation, D.K.; writing—original draft preparation, D.K. and M.P.; writingreview and editing, D.K., M.P. and A.K.; visualization, D.K. and M.P.; supervision, A.K.; project administration, D.K. and A.K.; funding acquisition, A.K. All authors have read and agreed to the published version of the manuscript.

Funding: This research was funded by EPRSC Doctoral Training Partnership (EP/R513209/1) and the EPSRC Centre for Energy System Integration (EP/P001173/1).

Institutional Review Board Statement: Not applicable.

Informed Consent Statement: Not applicable.

Data Availability Statement: The data presented in this study are openly available in DataShare at https://doi.org/10.7488/ds/2979 [9].

Acknowledgments: The authors would like to acknowledge Elexon and Energy Stats UK as this paper contains BMRS data $\odot$ (Elexon Limited copyright and database right [2020]) and Octopus Agile tariff data provided by the energy-stats.uk website. 
Conflicts of Interest: The authors declare no conflict of interest. The funders had no role in the design of the study; in the collection, analyses or interpretation of data; in the writing of the manuscript, or in the decision to publish the results.

\section{References}

1. British Foreign Policy Group. COVID-19 Timeline. Available online: https://bfpg.co.uk/2020/04/covid-19-timeline/ (accessed on 11 November 2020).

2. Winchester, L. Lights Out. Energy Firms Warn of Blackouts Plunging Coronavirus Lockdown Brits into Darkness. Sun, 31 March 2020. Available online: https:/ / www.thesun.co.uk/money/11292200/coronavirus-energy-electricity-blackout/ (accessed on 20 January 2021).

3. Panteli, M.; Pickering, C.; Wilkinson, S.; Dawson, R.; Mancarella, P. Power System Resilience to Extreme Weather: Fragility Modeling, Probabilistic Impact Assessment, and Adaptation Measures. IEEE Trans. Power Syst. 2017, 32, $3747-3757$. [CrossRef]

4. Electrical Power Research Institute (EPRI). COVID-19 Bulk System Impacts Demand Impacts and Operational and Control Center Practices. In Technical Report; Electrical Power Research Institute: Palo Alto, CA, USA, 2020. Available online: http:/ / mydocs.epri.com/docs/public/covid19/3002018602R2.pdf (accessed on 11 November 2020).

5. National Grid ESO. The 'Lockdown Effect' on TV Viewing Habits and the Electricity Grid. Available online: https://www. nationalgrideso.com/news/lockdown-effect-tv-viewing-habits-and-electricity-grid (accessed on 20 January 2021).

6. Aurora Energy Research. Impact of Coronavirus on European energy markets. In Technical Report; Aurora Energy Research: Oxford, UK, 2020. Available online: https:/ /www.auroraer.com/wp-content/uploads/2020/04/Aurora-COVID-19-weeklyimpact-tracker-150420-FINAL.pdf (accessed on 11 November 2020).

7. Elexon. Highest System Price Since 19 Years; Technical Report; Elexon: London, UK, 2020. Available online: https:/ /www.elexon. co.uk/article/elexon-insight-highest-system-price-in-... (accessed on 11 November 2020).

8. Kirli, D. Electricity Data Pipeline. Available online: https://github.com/desenk/Electricity-Data-Pipeline (accessed on 11 November 2020).

9. Kirli, D.; Parzen, M.; Kiprakis, A. Dataset: Impact of the COVID-19 Lockdown on the Electricity System of Great Britain: A Study on Energy Demand, Generation, Pricing and Grid Stability, 2019-2020 [Dataset]. University of Edinburgh. School of Engineering. Institute for Energy Systems. Available online: https:/ / doi.org/10.7488/ds/2979. (accessed on 26 January 2020).

10. Elexon. BMRS API and Data Push User Guide. 2019. Available online: https://www.elexon.co.uk/documents/trainingguidance/bsc-guidance-notes/bmrs-api-and-data-push-user-guide-2/ (accessed on 11 November 2020).

11. Elexon. Balancing Market Reporting Service. 2020. Available online: https://www.bmreports.com/bmrs/?q=eds/main (accessed on 11 November 2020).

12. Government Agrees Measures with Energy Industry to Support Vulnerable People through COVID-19-GOV.UK. Available online: https:/ / www.gov.uk/government/news/government-agrees-measures-with-energy-industry-to-support-vulnerablepeople-through-covid-19 (accessed on 11 November 2020).

13. Elexon. BMRS: Temperature Data. Available online: https://www.bmreports.com/bmrs/?q=generation/tempraturedata (accessed on 20 January 2021).

14. Thornton, H.E.; Hoskins, B.J.; Scaife, A.A. The role of temperature in the variability and extremes of electricity and gas demand in Great Britain. Environ. Res. Lett. 2016, 11, 114015. [CrossRef]

15. Hirth, L. The Economics of Wind and Solar Variability. In Technical Report; Technical University Berlin: Berlin, Germany, 2014. Available online: https:/ / neon.energy /Hirth-2014-Economics-Wind-Solar-Variability-Value-Deployment-Costs.pdf (accessed on 11 November 2020).

16. International Energy Agency. Re-Powering Markets. Market Design and Regulation during the Transition to Low-Carbon Power Systems; Technical Report; IEA: Paris, France, 2016.

17. Cochran, J. Market Evolution: Wholesale Electricity Market Design for 21st Century Power Systems; Technical Report; NREL: Golden, CO, USA, 2013. Available online: https:/ / www.nrel.gov/docs/fy14osti/57477.pdf (accessed on 11 November 2020).

18. Ela, E.; Milligan, M.; Kirby, B. Operating Reserves and Variable Generation: A Comprehensive Review of Current Strategies, Studies, and Fundamental Research on the Impact that Increased Penetration of Variable Renewable Generation has on Power System Operating Reserves; Technical Report; NREL: Golden, CO, USA, 2011. Available online: https:/ /www.nrel.gov/docs/fy11osti/51978.pdf (accessed on 11 November 2020).

19. National Grid. Balancing Services Adjustment Data Methodology Statement. 2018. Available online: https://www. nationalgrideso.com/document/94856/download (accessed on 11 November 2020).

20. Hansen, A.D.; Altin, M.; Margaris, I.D.; Iov, F.; Tarnowski, G.C. Analysis of the short-term overproduction capability of variable speed wind turbines. Renew. Energy 2014, 68, 326-336. [CrossRef]

21. Zeni, L.; Rudolph, A.J.; Münster-Swendsen, J.; Margaris, I.; Hansen, A.D.; Sørensen, P. Virtual inertia for variable speed wind turbines. Wind Energy 2013, 16, 1225-1239. [CrossRef]

22. Liu, J.; Yang, D.; Yao, W.; Fang, R.; Zhao, H.; Wang, B. PV-based virtual synchronous generator with variable inertia to enhance power system transient stability utilizing the energy storage system. Prot. Control Mod. Power Syst. 2017, 2, 39. [CrossRef] 
23. Sahay, K.B.; Tripathi, M.M. Day ahead hourly load forecast of PJM electricity market and iso new england market by using artificial neural network. In Innovative Smart Grid Technologies; IEEE: Washington, DC, USA, 2014; pp. 1-5. [CrossRef]

24. Khuntia, S.R.; Rueda, J.L.; van der Meijden, M.A. Forecasting the load of electrical power systems in mid- and long-term horizons: A review. IET Gener. Transm. Distrib. 2016, 10, 3971-3977. [CrossRef]

25. He, F.; Zhou, J.; Mo, L.; Feng, K.; Liu, G.; He, Z. Day-ahead short-term load probability density forecasting method with a decomposition-based quantile regression forest. Appl. Energy 2020, 262. [CrossRef]

26. Tofallis, C. A better measure of relative prediction accuracy for model selection and model estimation. J. Oper. Res. Soc. 2015, 66, 1352-1362. [CrossRef]

27. National Grid ESO. Quarterly Forecasting Report-March 18. 2018. Available online: https://www.nationalgrideso.com/sites/ eso/files/documents /Quarterly\%20Forecasting\%20Report\%20-\%20March18.pdf (accessed on 11 November 2020).

28. National Grid ESO. Energy Forecasting Strategic Project Roadmap; Technical Report; National Grid ESO: Warwick, UK, 2019. Available online: https:/ / demandforecast.nationalgrid.com/efs_demand_forecast/downloadfile?filename=Energy $\% 20$ Forecasting\%20Strategic\%20Project\%20Roadmap_1561466731012.pdf (accessed on 11 November 2020).

29. Elexon. Guidance Imbalance Pricing Guidance in Great Britain. 2019. Available online: https:/ /www.elexon.co.uk/documents/ training-guidance/bsc-guidance-notes/imbalance-pricing/ (accessed on 11 November 2020).

30. Elexon. Loss of Load Probability Calculation Statement. 2019. Available online: https://www.elexon.co.uk/documents/bsccodes/lolp/loss-of-load-probability-calculation-statement/ (accessed on 11 November 2020).

31. Maekawa, J.; Hai, B.H.; Shinkuma, S.; Shimada, K. The effect of renewable energy generation on the electric power spot price of the Japan electric power exchange. Energies 2018, 11, 2215. [CrossRef]

32. National Grid. Procurement Guidelines SO. 2017. Available online: http://www2.nationalgrid.com/UK/Industry-information (accessed on 11 November 2020).

33. National Grid. Wider Access to Balancing Mechanism Roadmap; Technical Report; National Grid: Warwick, UK, 2018. Available online: https: / /www.nationalgrid.com/sites/default/files/documents/Wider20BM20Access20Roadmap_FINAL.pdf (accessed on 24 November 2020).

34. National Grid. Wider Access to the GB Balancing Mechanism and TERRE-Review and Update; Technical Report; National Grid: Warwick, UK, 2020.

35. Campillo, J.; Dahlquist, E.; Wallin, F.; Vassileva, I. Is real-time electricity pricing suitable for residential users without demand-side management? Energy 2016, 109, 310-325. [CrossRef]

36. Octopus Energy. Agile Pricing. Available online: https://octopus.energy/blog/agile-pricing-explained/ (accessed on 11 November 2020).

37. Zarch. Energy Stats UK. Available online: https://www.energy-stats.uk/ (accessed on 11 November 2020).

38. Igor Todorović. Birol: COVID-19 shock shows renewables' importance for power balance. Balkan Green Energy News, 2020. Available online: https:/ / balkangreenenergynews.com/birol-covid-19-shock-shows-renewables-importance-for-power-balance/ (accessed on 11 November 2020).

39. Staffell, I.; Pfenninger, S. The increasing impact of weather on electricity supply and demand. Energy 2018, 145, 65-78. [CrossRef]

40. Mukherjee, J.C.; Gupta, A. A Review of Charge Scheduling of Electric Vehicles in Smart Grid. IEEE Syst. J. 2015, 9, 1541-1553. [CrossRef]

41. Kirli, D.; Kiprakis, A. Techno-economic potential of battery energy storage systems in frequency response and balancing mechanism actions. J. Eng. 2020, 2020, 774-782. [CrossRef]

42. Snow, S.; Bean, R.; Glencross, M.; Horrocks, N. Drivers behind Residential Electricity Demand Fluctuations Due to COVID-19 Restrictions. Energies 2020, 13, 5738. [CrossRef]

43. Ghiani, E.; Galici, M.; Mureddu, M.; Pilo, F. Impact on Electricity Consumption and Market Pricing of Energy and Ancillary Services during Pandemic of COVID-19 in Italy. Energies 2020, 13, 3357. [CrossRef] 